\title{
Optimizing the Architecture of Lung-Inspired Fuel Cells
}

\author{
J. I. S. Cho ${ }^{a, b, \dagger}$, J. Marquis ${ }^{c, \dagger}$, P. Trogadas ${ }^{a, b}$, T. P. Neville ${ }^{b}$, D. J. L. Brett ${ }^{b}$, M.-O. Coppens*a \\ a. $\quad$ EPSRC “Frontier Engineering” Centre for Nature Inspired Engineering \& \\ Department of Chemical Engineering, University College London, London WC1E 7JE, \\ $U K$ \\ b. Electrochemical Innovation Lab, Department of Chemical Engineering, \\ University College London, London WC1E 7JE, UK \\ c. Department of Chemical and Biological Engineering, Rensselaer Polytechnic \\ Institute, Troy, NY 12180, USA [current address: Momentive Performance Materials, \\ Waterford, NY 12188, USA] \\ $\dagger$ Both authors contributed equally \\ * Corresponding author: Tel.: +44 (0)20 31081126 / 7679 3824; Fax: +44 (0)20 76797369. \\ E-mail address: m.coppens@ucl.ac.uk
}

\begin{abstract}
A finite-element model of a polymer electrolyte membrane fuel cell (PEMFC) with fractal branching, lung-inspired flow-field is presented. The effect of the number of branching generations $N$ on the thickness of the gas diffusion layer (GDL) and fuel cell performance is determined. Introduction of a fractal flow-field to homogenize reactant concentration at the flow-field | GDL interface allows for the use of thinner GDLs. The model is coupled with an optimized cathode catalyst layer microstructure with respect to platinum utilization and power density, revealing that the $2020 \mathrm{DoE}$ target of $\sim 8 \mathrm{~kW} / \mathrm{g}_{\mathrm{Pt}}$ is met at $N=4$ generations, and a platinum utilization of $\sim 36 \mathrm{~kW} / \mathrm{g}_{\mathrm{Pt}}$ is achieved at $N=6$ generations. In terms of the overall fuel cell stack architecture, our results indicate that either the platinum loading or the number of cells in the stack can be reduced by $\sim 75 \%$, the latter option of which, when combined with a $100 \mu \mathrm{m}$ GDL, can lead to $>80 \%$ increase in the volumetric power density of the fuel cell stack.
\end{abstract}

Keywords: Lung-Inspired; Fractal; Flow-Field; Gas Diffusion Layer; Pt Utilization 


\section{1. Introduction}

35 As global energy demands continue to rise, the need for viable alternative energy technologies 36 is at an all-time high. Fuel cells have been amongst the most promising candidates for 37 supplying reliable, clean, and efficient energy for a variety of applications, ranging from 38 personal electronics to cars, homes, and larger commercial power generation. Decades of research have led to design improvements that leave fuel cell technology on the cusp of economic viability [1].

Despite the major advancements made over several decades to improve fuel cell performance and reliability, nearly all polymer electrolyte membrane fuel cell (PEMFC) designs suffer from the same fundamental flaw - depletion of reactant concentration along the flow path of the flow-field [2-5]. Within the confines of traditional flow-field geometries, such as serpentine and parallel, this is an unavoidable side effect. Uneven gas distribution in the flow-fields leads to fuel starvation, which is one of the main causes of component and performance degradation of a fuel cell [6-13]. Efforts to mitigate mass transport losses have led to the development of various flow-field designs [2, 3, 14-19].

Recently, we proposed a nature-inspired engineering methodology that addresses the uneven reactant distribution issues in fuel cells (Fig. 1) [20]. This is the first fuel cell design approach of its kind that is rooted in the mechanistic understanding of the structure of the respiratory organ. The characteristics of the lung to transition from fractal branching, bronchial airways to uniformly distributed acinar airways, corresponding to a transition from convective to diffusive transport (Péclet number, Pé $\sim 1$ ) and deliver oxygen uniformly over its entire structure to achieve minimal global entropy production $[10,21,22]$, served as a guide towards the design of fractal flow-fields. This nature-inspired engineering approach stands in firm contrast to

57 heuristic approaches that imitate biological features, by copying the apparent structure of 
natural fluid distribution systems (e.g., lungs, leaves, and veins) without formal mathematical description or methodology to guide the design of such flow-fields [2, 17, 23-28]. The lunginspired flow-field design differentiates itself from conventional design approaches, which involve empirical alteration of the channel configurations to achieve more uniform gas distribution, but typically result in a higher pressure drop [29-31] and ineffective water and heat management $[29,30]$. Numerical simulations of the lung-inspired flow-field based PEMFCs revealed that the ideal number of branching generations $(N)$ for minimum entropy production lies between $N=5$ and 7. Guided by the simulation results, three flow-fields with $N=3,4$, and 5 were 3D printed via direct metal laser sintering (DMLS) and tested against serpentine flow-fields. The $N=4$ fractal flow-field demonstrated, respectively, $\sim 20 \%$ and $\sim$ $30 \%$ increase in current density and maximum power density over serpentine flow-fields above $0.8 \mathrm{~A} \mathrm{~cm}^{-2}[20]$.

(a)

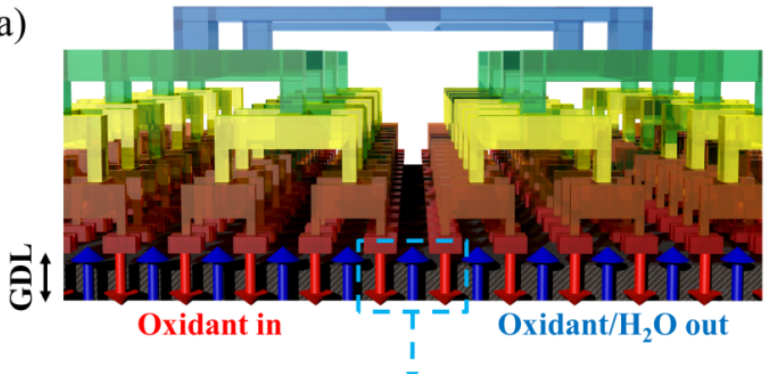

(b)

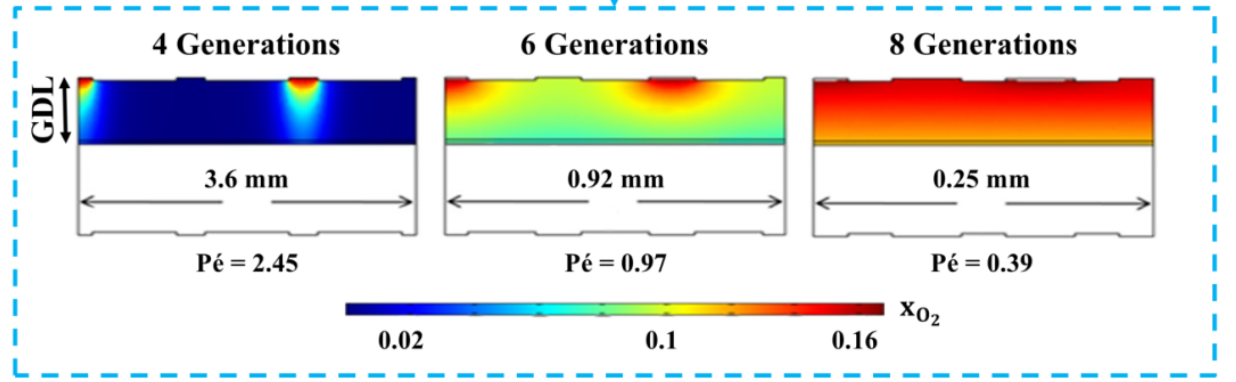

Fig. 1. (a) A computer generated image of the GDL integrated with a fractal flow-field with $N$ $=4$ generations, and (b) numerical simulations conducted in our previous study illustrating oxygen mass fraction distribution in the cathode catalyst layer using fractal flow-fields with $N$ $=4,6$, and 8 generations [20]. Copyright (C) 2018 The Royal Society of Chemistry.

To further improve the fuel cell performance realized from uniform reactant distribution, the electrode structure and composition can be tailored. The electrode of a fuel cell consists of two 
main components, namely the gas diffusion layer (GDL) and the catalyst layer (CL). The GDL is typically a carbon fiber sheet treated with polytetrafluoroethylene (PTFE) that provides structural support for the membrane electrode assembly (MEA), while allowing gas and electrical transport to and from the catalyst layer [32]. Although the GDL is a seemingly minor component of a fuel cell, studies report that altering its structural properties (such as porosity, PTFE content, and thickness) can substantially affect fuel cell performance [32-34]. Additional gain in performance can be achieved via modification of the CL microstructure to improve catalyst utilization at reduced loading [35].

Several models have been developed to explore the optimum composition and structure of the cathode catalyst layer in a PEMFC. These can be categorized as interface $[36,37]$, pseudohomogeneous [38-42], and agglomerate models [43-50]. Agglomerate models are usually employed due to the better representation of the cathode catalyst layer than the other models, resulting in good agreement with experimental data $[39,51]$. This work introduces a finiteelement model of a lung-inspired flow-field based PEMFC, and examines the effect of the number of generations $N$ on the thickness of the GDL and the fuel cell performance. Lunginspired flow-fields perform some of the tasks of the GDL, such as homogenizing reactant concentration, and reducing flow velocity prior to entering the catalyst layer. As a result, thinner GDLs can be used, allowing for a higher concentration of oxygen to reach the catalyst layer. To investigate the effect of the number of generations $N$ on platinum utilization, a finiteelement model is combined with a two-phase agglomerate model [35] with optimized cathode catalyst layer microstructure. 


\section{Mathematical model of the flow-field}

\subsection{Modeling domain}

104 The modeling domain consists of the GDL and CL at the anode and cathode, as well as the

105 polymer electrolyte membrane (Fig. 2). The MEA is located in between fractal flow-fields with

106 a surface area of $10 \mathrm{~cm}^{2}$, which are represented by arrows that correspond to the location of the

107 fractal inlet and outlet channels.

108 The model captures the effects of varying the number of branching generations $N$ on fuel cell

109 performance by "zooming in" on the flow-field outlets, such that the number of inlets and

110 outlets being modeled remains the same for any given number of generations. However, the

111 size of the modeling domain, along with the size of the inlets, outlets, and land area, changes

112 with each additional generation (Fig. 2). The thickness of the GDL, CL, and polymer

113 electrolyte membrane remains constant, regardless of the number of generations being modeled.

114 Due to the symmetry associated with the fractal design, the results from the modeled section

115 can be extrapolated to locally resolve fuel cell performance throughout the entire cell.

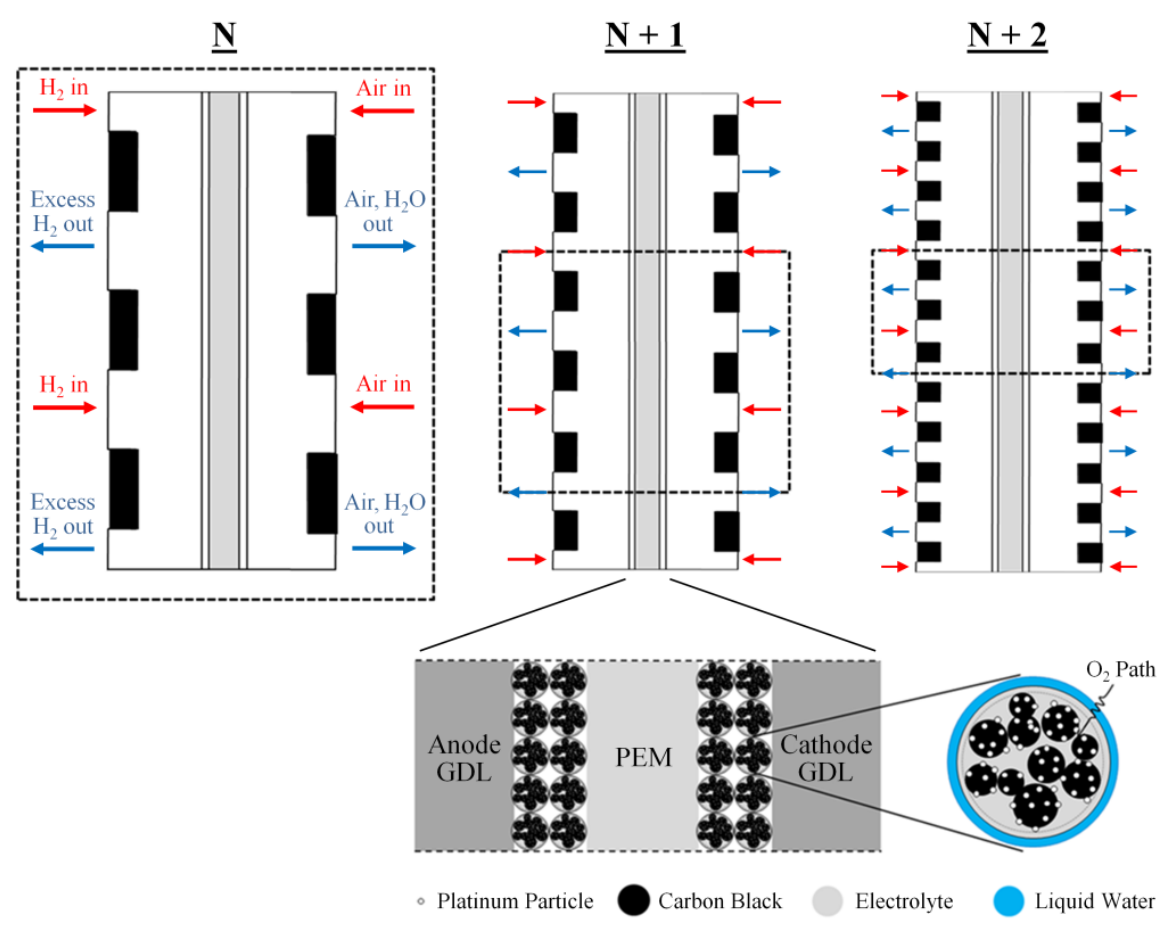


117 Fig. 2. Schematic of the modeling domain of the lung-inspired flow-field based PEMFC at

118 various generations $N$. The rectangular box shows what is actually being modeled [20].

119 2.2. Modeling assumptions

120 The main modeling assumptions are as follows [52, 53]:

121 Table 1. Assumptions used in the model

- Steady state

- Isothermal operation

- Ideal gases

- Fully humidified inlet gases

- Fully hydrated polymer electrolyte membrane (Nafion)

- Uniform catalyst nanoparticle size and uniform Nafion film thickness on these nanoparticles

- No gas crossover

- Liquid water is only present in the cathode

- High enough electrical conductivity of the electrode to neglect electrical resistance

- Negligible contact resistance between the flow-fields and MEA

- Knudsen effects were not taken into account to simplify the model, as in $[54,55]$

122

123 Isothermal operation is a reasonable assumption for fuel cell simulation on a local scale where

124 numerous studies report a maximum temperature difference of less than $3 \mathrm{~K}$ within an MEA

125 [56-58]. This assumption is especially well-suited to our fractal flow-field model, due to the

126 symmetry associated with the fractal design.

127 Table 2. Parameters used in the model.

\begin{tabular}{llllllll}
\hline Geometry & Value & Units & Source & Parameter & Value & Units & Source \\
\hline$A$ & $10^{-3}$ & $\mathrm{~m}^{2}$ & & $t_{G D L}$ & $350 \times 10^{-6}$ & $\mathrm{~m}$ & {$[59]$} \\
$r_{a g g}$ & $150 \times 10^{-9}$ & $\mathrm{~m}$ & {$[35]$} & $t_{C L}$ & $40 \times 10^{-6}$ & $\mathrm{~m}$ & {$[60]$} \\
$W_{c, 1}$ & $0.25 \times 10^{-2}$ & $\mathrm{~m}$ & & $t_{m e m}$ & $150 \times 10^{-6}$ & $\mathrm{~m}$ & {$[61]$} \\
\multicolumn{2}{l}{ Operating conditions } & & & & & & \\
$P$ & 1.1 & $\mathrm{~atm}$ & {$[62]$} & $x_{O 2}$ & 0.11 & - & {$[35]$} \\
$T$ & 353 & $\mathrm{~K}$ & {$[63]$} & $x_{N 2}$ & 0.42 & - & {$[35]$} \\
$S_{\text {Cathode }}$ & 2.0 & - & {$[64]$} & $x_{w}$ & 0.47 & - & {$[35]$} \\
$S_{\text {Anode }}$ & 2.0 & - & {$[65]$} & $U_{\text {ref }}$ & 1.0 & $\mathrm{~V}$ & {$[53]$}
\end{tabular}




\begin{tabular}{|c|c|c|c|c|c|c|c|}
\hline \multicolumn{8}{|c|}{ Physical properties } \\
\hline$C_{O 2, r e f}$ & 0.85 & $\mathrm{~mol} \mathrm{~m}^{-3}$ & {$[63]$} & $i_{0, c, 273}$ & $1.0 \times 10^{-2}$ & $\mathrm{~A} \mathrm{~m}^{-2}$ & [53] \\
\hline$C_{H 2, \text { ref }}$ & 56.4 & $\mathrm{~mol} \mathrm{~m}^{-3}$ & {$[66]$} & $i_{0, c}$ & $i_{0, c, 273} \times 2^{(\mathrm{T}-273) / 10}$ & $\mathrm{~A} \mathrm{~m}^{-2}$ & [67] \\
\hline$\alpha_{c}$ & 1.0 & - & [64] & $i_{0, a}$ & $1.0 \times 10^{2}$ & $\mathrm{~A} \mathrm{~m}^{-2}$ & [40] \\
\hline$\alpha_{a}$ & 0.5 & - & {$[52]$} & $\mu_{w}$ & $3.5 \times 10^{-4}$ & $\mathrm{~kg} \mathrm{~m}^{-1} \mathrm{~s}^{-1}$ & [68] \\
\hline$H_{H 2}$ & $4.5 \times 10^{-2}$ & atm $\mathrm{m}^{3} \mathrm{~mol}^{-1}$ & {$[66]$} & $\rho_{C}$ & $2.0 \times 10^{3}$ & $\mathrm{~kg} \mathrm{~m}^{-3}$ & [63] \\
\hline $\mathrm{H}_{\mathrm{O} 2}$ & $3.56 \times 10^{-1}$ & atm m $\mathrm{mol}^{-1}$ & [69] & $\rho_{P t}$ & $2.15 \times 10^{4}$ & $\mathrm{~kg} \mathrm{~m}^{-3}$ & [63] \\
\hline$n$ & $0.11 \times \lambda$ & - & [70] & $\varepsilon_{V, G D L}$ & 0.75 & - & [71] \\
\hline$\lambda$ & $\mathrm{C}_{\mathrm{W}, \mathrm{N}} / \mathrm{C}_{\mathrm{f}}$ & - & {$[53]$} & $\varepsilon_{V, C L}$ & 0.5 & - & [35] \\
\hline$C_{W, N}$ & $4.2 \times 10^{3}$ & $\mathrm{~mol} \mathrm{~m}^{-3}$ & [53] & $\varepsilon_{a g g, N}$ & 0.66 & - & [35] \\
\hline$C_{f}$ & $1.2 \times 10^{3}$ & $\mathrm{~mol} \mathrm{~m}^{-3}$ & {$[53]$} & $m_{p t}$ & $4.0 \times 10^{-3}$ & $\mathrm{~kg} \mathrm{~m}^{-2}$ & [35] \\
\hline$k_{v}$ & 100 & $\mathrm{~atm}^{-1} \mathrm{~s}^{-1}$ & [53] & $k_{c}$ & 100 & $\mathrm{~s}^{-1}$ & [53] \\
\hline$P t \mid C$ & 0.28 & - & {$[35]$} & & & & \\
\hline \multicolumn{8}{|c|}{ Transport properties } \\
\hline$K_{w, 0-G D L}$ & $2.0 \times 10^{-15}$ & $\mathrm{~m}^{2}$ & {$[53]$} & $D_{\mathrm{O}, \mathrm{H} 2 \mathrm{O}}$ & $2.82 \times 10^{-5} \times(\mathrm{T} / 308.1)^{1.5}$ & $\mathrm{~m}^{2} \mathrm{~s}^{-1}$ & [72] \\
\hline$K_{w, 0-C L}$ & $5.0 \times 10^{-17}$ & $\mathrm{~m}^{2}$ & {$[53]$} & $D_{O 2, N 2}$ & $2.2 \times 10^{-5} \times(\mathrm{T} / 293.2)^{1.5}$ & $\mathrm{~m}^{2} \mathrm{~s}^{-1}$ & [72] \\
\hline$\sigma_{m}$ & 8.9 & $\mathrm{~S} \mathrm{~m}^{-1}$ & [35] & $D_{N 2, H 2 O}$ & $2.56 \times 10^{-5} \times(\mathrm{T} / 307.5)^{1.5}$ & $\mathrm{~m}^{2} \mathrm{~s}^{-1}$ & {$[72]$} \\
\hline$\sigma_{s}$ & 1000 & $\mathrm{~S} \mathrm{~m}^{-1}$ & [73] & $D_{H 2, H 2 O}$ & $9.15 \times 10^{-5} \times(\mathrm{T} / 307.5)^{1.5}$ & $\mathrm{~m}^{2} \mathrm{~s}^{-1}$ & [72] \\
\hline$D_{O 2, w}$ & $4.73 \times 10^{-9}$ & $\mathrm{~m}^{2} \mathrm{~s}^{-1}$ & [35] & $D_{O 2, N}$ & $8.45 \times 10^{-10}$ & $\mathrm{~m}^{2} \mathrm{~s}^{-1}$ & [63] \\
\hline
\end{tabular}

129 The fractal flow-fields comprise self-similar, repeatedly branching " $\mathrm{H}$ " shaped channels

130 designed to uniformly distribute reactants across the catalyst layer surface [20, 21] (Fig. 3).

131 This channel geometry allows a single inlet to branch into $4^{N}$ outlets via flow paths that are all

132 equal in length. The fractal similarity dimension, $D$, is calculated by [74]:

$133 D=\frac{\log (n)}{\log \left(\frac{1}{s}\right)}=\frac{\log (4)}{\log (2)}=2$

134 where $n$ is the number of daughter shapes per parent, and $s$ is the contraction ratio between

135 daughter and parent. The fractal dimension, $D$, is a measure for the space-filling capacity of an

136 object; for self-similar objects, in which parts of the object are invariant under magnification,

137 as in this recursively constructed tree, $D$ is calculated by the above expression [74]. Contrary

138 to classical objects from Euclidean geometry, the dimension of a fractal object is greater than

139 its topological dimension [75], which would be 1 for a line, and can take non-integer values.

140 The highest possible value of $D$ is the dimension of the embedding space, which 2 for a plane,

141 so, generally, $1 \leq D \leq 2$. The more the tree tends to occupy the plane, the higher the value of $D$ 
142 [76]. In our case, $D=2$ indicates that, for an infinite number of generations, the branching tree 143 would become plane-filling. Reactant depletion over the channel path is eliminated with this 144 fractal structure, as only the outlets of the fractal distributor are open to the active area.

145

146

147

148

149

150

151

152

$154 \quad r_{p}^{3}=\sum_{i=1}^{n} r_{d_{i}}^{3}$ 80]:

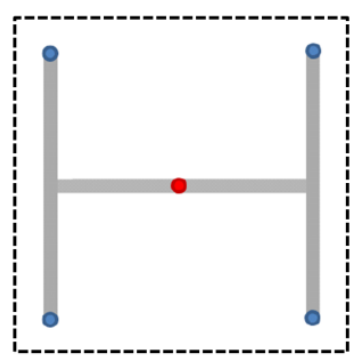

$\mathrm{N}=1$

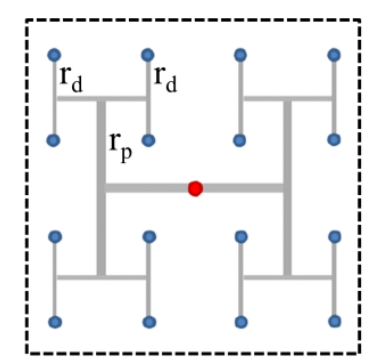

$\mathrm{N}=2$

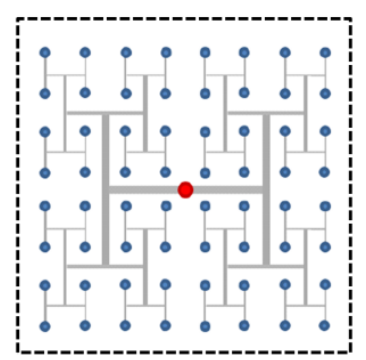

$\mathrm{N}=3$

Fig. 3. Fractal structures of different generations $N$ for gas distribution networks in PEMFCs. Red and blue dots represent fluid inlet and outlets, respectively, and dashed boxes represent active membrane area. Each $H$ shape represents 4 daughter branches of radius $r_{d}$; the radius of each branch in an $\mathrm{H}$ shape is the same, including the horizontal channel.

Similar to the lung, the width of the channels in the fractal flow-fields was scaled by adopting Murray's law, which dictates a cubic relationship between hydraulic diameters of parent and daughter branches, leading to minimum mechanical energy and thermodynamic losses [74, 77 -

Here, $r_{p}(\mathrm{~m})$ and $r_{d}(\mathrm{~m})$ are the radii of the parent and $n$ daughter branches, respectively (here, $n=4)$. By following Murray's law, the scaling of the channel diameters leads to a reduction in flow velocity at each generation, due to a net increase in cross-sectional area. Similar scaling of the channel lengths leads to a constant pressure drop over each generation of the branching network, which minimizes the pressure drop required to drive the flow across the system [78]. This resembles the transition in flow regimes between bronchial tree (convection) and alveoli

161 (diffusion) in the human lung, where gas transport has been shown to be optimal based on 162 irreversible thermodynamics [78]. 
163 The ratio of convective and diffusive fluxes in the last generation of the fractal flow-field is

164 characterized by the dimensionless Péclet number, defined as:

$165 P e ́=\frac{L \cdot U}{\mathrm{D}}$

166 where $L(\mathrm{~m})$ is the GDL thickness, $U\left(\mathrm{~m} \mathrm{~s}^{-1}\right)$ is the average gas velocity within the GDL, and

$167 \mathcal{D}\left(\mathrm{m}^{2} \mathrm{~s}^{-1}\right)$ is the diffusivity. The flow velocity at the flow-field | GDL interface is calculated 168 using:

$169 \quad U=\frac{Q_{0}}{A_{N} \cdot 4^{N}}$

170 where $Q_{0}\left(\mathrm{~m}^{3} \mathrm{~s}^{-1}\right)$ is the volumetric flow rate of gas at the inlet, and $A_{N}\left(\mathrm{~m}^{2}\right)$ is the cross-sectional

171 area of a single fractal outlet at the $N^{\text {th }}$ generation. Eq. (4) determines the gas flow velocity at

172 the GDL | flow-field inlet boundary. The velocity calculated using this equation is valid for all

173 individual fractal outlets, since the distance between the fractal inlet and individual outlet

174 channels is exactly the same, thus, allowing for equal distribution of inlet gas and equal velocity

175 through individual outlet channels. The optimal number of fractal generations, $N$, in the flow-

176 field is such that transport transitions from convective to diffusive, corresponding to a local Pé

$177 \sim 1$. For Pé numbers less than $1($ Pé $<1)$, transport resistance in the finer channels would 178 increase unnecessarily.

179 2.4. Governing equations for saturated agglomerate model

180 A steady-state, two-phase, two-dimensional saturated agglomerate model has been employed

181 to model transport and reaction in the catalyst layer [53], while a modified reaction term [35],

182 detailed in the further described Eq. (21), is incorporated to account for the spherical geometry

183 of the catalyst agglomerates (Fig. 4). 


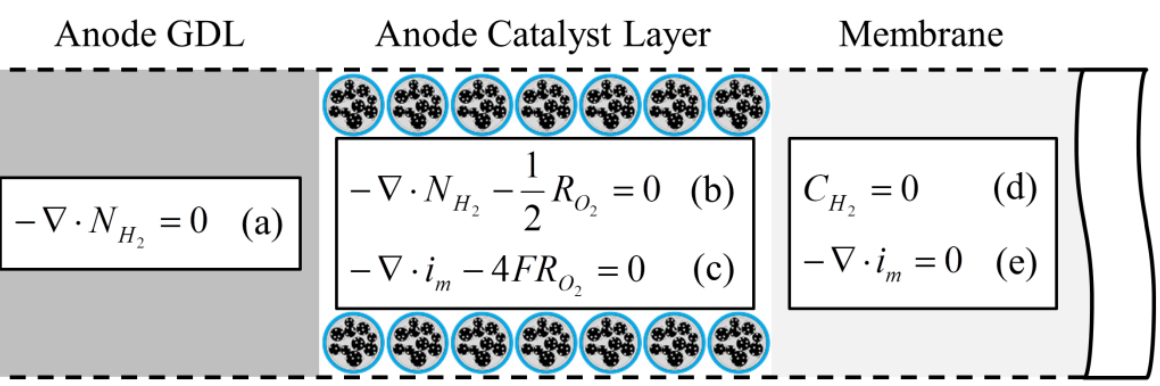

184

Membrane

Cathode Catalyst Layer

Cathode GDL

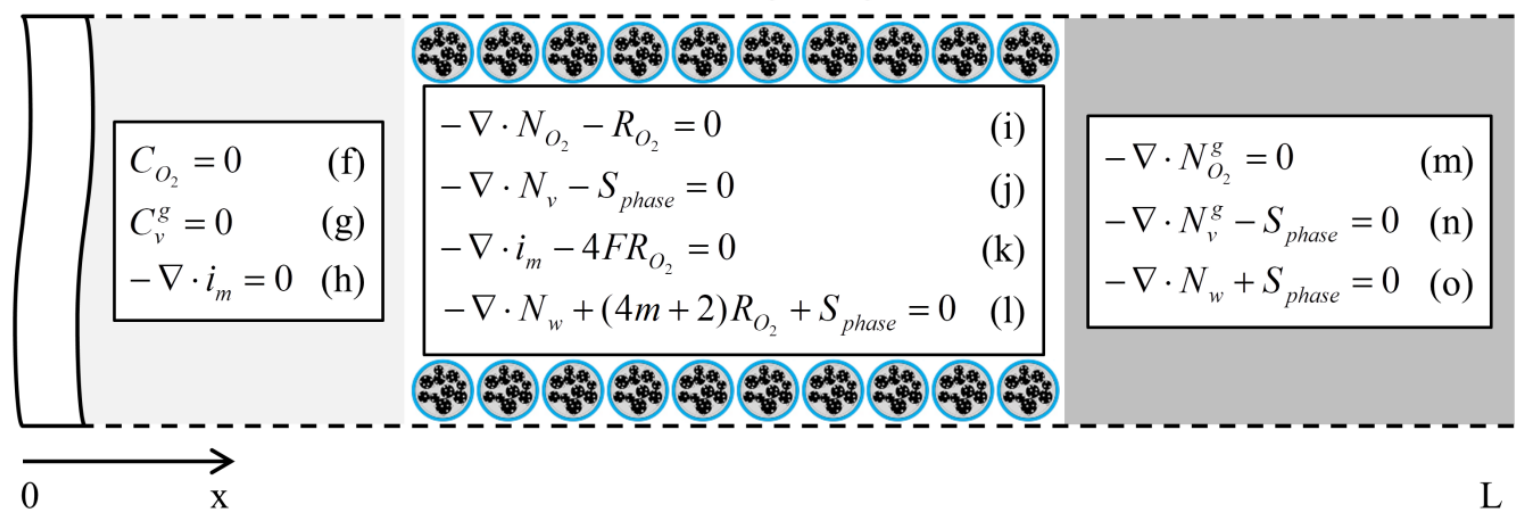

185 Fig. 4. Summary of governing equations in each domain of the PEMFC. All the terms are 186 presented in detail in the following sections. Domains are not drawn to scale.

187 2.4.1. Transport of gas species within the GDL and CL

188 The continuity equation (Eq. 5) and Darcy's law (Eq. 6) are used to evaluate the velocity and

189 pressure profiles of the gaseous mixture inside the porous media:

190

$\nabla \cdot\left(\rho_{g} \cdot u_{g}\right)=0$

191

$u_{g}=\frac{-k_{p}}{\mu_{g}} \cdot \nabla P$

192 where $\rho_{g}\left(\mathrm{~kg} \mathrm{~m}^{-3}\right), u_{g}\left(\mathrm{~m} \mathrm{~s}^{-1}\right)$, and $\mu_{g}(\mathrm{~Pa} \mathrm{~s})$ are the density, velocity, and viscosity of the gaseous

193 mixture, respectively, $k_{p}\left(\mathrm{~m}^{2}\right)$ is the permeability of the porous medium, and $P(\mathrm{~Pa})$ is the

194 pressure. The Stefan-Maxwell equations are used to describe the multi-component diffusion:

195

$\nabla x_{i}=\sum_{j=1, j \neq i} \frac{1}{C \cdot D_{i j}^{e f f}} \cdot\left(x_{i} \cdot N_{j}-x_{j} \cdot N_{i}\right)$ 
where $D_{i j}^{e f f}\left(\mathrm{~m}^{2} \mathrm{~s}^{-1}\right)$ is the effective binary diffusivity of species $i$ in species $j, x_{i}$ is the mole

197 fraction of species $i, N_{i}\left(\mathrm{~mol} \mathrm{~m}^{-2} \mathrm{~s}^{-1}\right)$ is the molar flux of species $i$, and $C\left(\mathrm{~mol} \mathrm{~m}^{-3}\right)$ is the total

198 molar concentration of gas. The transport of each gaseous species is governed by a general

199 convection-diffusion equation in conjunction with the Stefan-Maxwell equations to account for

200 multispecies diffusion:

201

$\nabla \cdot\left\{\frac{-\rho_{g} \cdot w_{i} \cdot \sum_{j} D_{i j}^{e f f}\left[\nabla x_{j}+\left(x_{j}-w_{j}\right) \cdot \nabla P\right]}{P}\right\}=M_{i} \cdot S_{i}-\rho \cdot u_{g} \cdot \nabla w_{i}$

202 where $w_{i}$ and $S_{i}\left(\mathrm{~kg} \mathrm{~m}^{-3} \mathrm{~s}^{-1}\right)$ are the mass fraction and source term of species $i$, respectively.

203 The Bruggeman correlation is used to calculate the effective gas diffusion coefficient [53, 81-

204 86], which accounts for the reduction in pore space available due to the presence of liquid water

205 within the porous media:

206

$D_{i j}^{e f f}=D_{i j} \cdot\left[\varepsilon^{v} \cdot(1-s)\right]^{1.5}$

207 where $\varepsilon^{v}, s$, and $D_{i j}\left(\mathrm{~m}^{2} \mathrm{~s}^{-1}\right)$ are the void fraction of the porous medium, saturation, and binary 208 diffusivity, respectively.

209 2.4.2. Transport of liquid water through the GDL and CL

210 Liquid water transport inside the GDL and catalyst layer is driven by capillary force and, hence,

211 Darcy's law is used to describe the flow of liquid inside the porous medium [53]:

212

$$
N_{w}=-\frac{\rho_{w}}{M_{w}} \cdot\left[\frac{K_{w}(s)}{\mu_{w}} \cdot \nabla P_{l}\right]
$$

213 where $P_{l}(\mathrm{~Pa}), \rho_{W}\left(\mathrm{~kg} \mathrm{~m}^{-3}\right), K_{W}\left(\mathrm{~m}^{2}\right), M_{W}\left(\mathrm{~kg} \mathrm{~mol}^{-1}\right)$, and $\mu_{W}(\mathrm{~Pa} \mathrm{~s})$ are the pressure, density,

214 permeability, molecular weight, and viscosity of liquid water, respectively. Analytical 215 equations (Eqs. 11-14) for the description of capillary pressure $\left(P_{c}\right)$, permeability of the porous 216 medium $\left(K_{W}\right)$, and capillary diffusion coefficient $\left(D_{c}\right)$ are listed below. 
217 The capillary pressure is expressed by the following empirical correlation [87]:

$218 \quad P_{c}(s)=P_{g}-P_{l}=d \cdot\left[e^{-a_{1}(s-c)}-e^{-a_{2}(s-c)}\right]+b$

219 where $s$ is the saturation level, $P_{g}(\mathrm{~Pa})$ is the gas phase pressure, and $a_{1}, a_{2}, b, c$, and $d$ are fitting 220 parameters (Table 3). The parameters used for the GDL have been obtained for carbon paper 221 type [53].

222 Table 3. Parameters for the capillary pressure correlation in the GDL and CL [53].

\begin{tabular}{llllll}
\hline Capillary function & $a_{1}$ & $a_{2}$ & $b(\mathrm{~Pa})$ & $c$ & $d(\mathrm{~Pa})$ \\
\hline GDL & -17.3 & -25.1 & 32.3 & 0.350 & -4.06 \\
Catalyst layer & -23.5 & -17.4 & 477 & 0.460 & -3.58 \\
\hline
\end{tabular}

223

224 The permeability of the porous medium depends on the liquid water saturation [87] as given 225 by Eq. (12):

$226 \quad K_{w}(s)=K_{w, 0} \cdot s^{4.5}$

227 where $K_{w, 0}\left(\mathrm{~m}^{2}\right)$ is the permeability of liquid water at $100 \%$ saturation level [88]. Substituting

228 Eqs. (11) and (12) into Eq. (10) yields the following expression for the liquid water flux:

229

$N_{w}=-\frac{\rho_{w} \cdot K_{w, 0}}{M_{w} \cdot \mu_{w}} \cdot s^{4.5} \cdot \nabla P_{c}=-D_{c} \cdot \frac{\rho_{w}}{M_{w}} \cdot \nabla s$

230 where the capillary diffusion coefficient, $D_{c}\left(\mathrm{~m}^{2} \mathrm{~s}^{-1}\right)$, is defined as [53]:

$231 \quad D_{c}=-\frac{K_{w, 0}}{\mu_{w}} \cdot \frac{d P_{c}}{d s} \cdot s^{4.5}$

232 Saturation is assumed to be continuous within the GDL and the CL. However, saturation is not

233 continuous at the GDL | CL interface, due to different pore sizes. This discontinuity is 234 accounted for by assuming equal capillary pressure at the GDL | CL interface, which results in 235 a saturation jump at the interface [53]. 
236 2.4.3. Transport of dissolved water through the polymer electrolyte membrane

237 The transport of dissolved water in the membrane is driven by electro-osmotic drag, diffusion 238 due to the concentration gradient, and hydraulic permeation. However, since the model 239 assumes fuel cell operation at constant pressure, the hydraulic permeation term is neglected.

240 Hence, the water flux in the membrane can be simplified to:

$241 \quad N_{w}^{N}=\frac{i_{N} \cdot m}{F}-D_{w}^{N} \cdot \nabla C_{w}^{N}$

242 where $i_{N}\left(\mathrm{~A} \mathrm{~m}^{-2}\right)$ is the electrolyte current density vector, $m$ is the electro-osmotic drag 243 coefficient, $D_{W}^{N}\left(\mathrm{~m}^{2} \mathrm{~s}^{-1}\right)$ and $C_{W}^{N}\left(\mathrm{~mol} \mathrm{~m}^{-3}\right)$ are the diffusivity and concentration of water in 244 membrane, respectively. At steady state, the flux of water is constant, so that, using Eq. (15):

$245 \nabla \cdot\left(\frac{i_{N} \cdot m}{F}\right)=0$

\subsubsection{Transport of charge}

247 The governing equations for the electronic and ionic charge transport are described using

248 Ohm's law as:

249

$i_{s}=-\sigma_{s} \cdot \nabla \phi_{s}$

$250 \quad i_{N}=-\sigma_{N} \cdot \nabla \phi_{N}$

251 where $\sigma_{s}$ and $\sigma_{N}\left(\mathrm{~S} \mathrm{~m}^{-1}\right)$ are the electronic and ionic conductivities, and $\phi_{\mathrm{s}}$ and $\phi_{\mathrm{N}}(\mathrm{V})$ are the

252 solid and electrolyte phase potentials, respectively. The charge balance equations (Eqs. 17 and

253 18) are solved to obtain solid and electrolyte phase potentials:

$254 \nabla \cdot\left(-\sigma_{N} \cdot \nabla \phi_{N}\right)=S_{\phi}$

$255 \nabla \cdot\left(-\sigma_{s} \cdot \nabla \phi_{s}\right)=-S_{\phi}$

256 In the catalyst layer, the source term $S_{\phi}$ represents the rate of reaction, $4 F R_{O 2}\left(\mathrm{~A} \mathrm{~m}^{-3}\right) . S_{\phi}$ is zero 257 in the polymer electrolyte membrane and GDL, as no reaction takes place in these domains. 
259 Assuming that the catalyst layer comprises a continuum of individual spherical catalyst 260 agglomerates, the oxygen reduction reaction rate $\left(\mathrm{mol} \mathrm{m}^{-3} \mathrm{~s}^{-1}\right)$ can be described by [35]:

$$
R_{O_{2}}=\left[\frac{\frac{R \cdot T}{H_{O_{2}}}}{\frac{\delta_{N} \cdot\left(\delta_{N}+r_{a g g}\right)}{r_{a g g} \cdot a_{r} \cdot D_{O_{2}}^{N}}+\frac{\delta_{w} \cdot\left(\delta_{w}+\delta_{N}+r_{a g g}\right)}{\left(\delta_{N}+r_{a g g}\right) \cdot a_{r} \cdot D_{O_{2}}^{w}}+\frac{1}{\xi \cdot k_{t}}}\right] \cdot C_{O_{2}}
$$

262 where $R\left(8.314 \mathrm{~J} \mathrm{~mol}^{-1} \mathrm{~K}^{-1}\right)$ is the universal gas constant, $H_{O 2}\left(\mathrm{~atm} \mathrm{~m}^{3} \mathrm{~mol}^{-1}\right)$ is Henry's constant

263 of oxygen between air and electrolyte [89-93], $\delta_{N}$ and $\delta_{w}(\mathrm{~m})$ are the ionomer and water film

264 thicknesses surrounding an agglomerate, $r_{a g g}(\mathrm{~m})$ is the agglomerate radius, $D_{O_{2}}^{N}$ and $D_{O_{2}}^{w}\left(\mathrm{~m}^{2} \mathrm{~s}^{-}\right.$

$\left.265^{1}\right)$ are the diffusivity of oxygen in ionomer and water, $a_{r}\left(\mathrm{~m}^{2} \mathrm{~m}^{-3}\right)$ is the effective agglomerate surface area, $\xi$ is the agglomerate effectiveness factor, and $k_{t}\left(\mathrm{~s}^{-1}\right)$ is the reaction rate constant.

267 The first and second term in the denominator describe the diffusion of oxygen through the water and ionomer film, while the final term accounts for diffusion and reaction inside the agglomerate. The reaction rate constant $k_{t}$ is expressed by:

$k_{t}=\left(1-\varepsilon_{v}^{C L}\right) \cdot \frac{a_{P t}^{a g g} \cdot i_{0, c}}{4 \cdot F \cdot C_{O_{2}}^{r e f}} \cdot \exp \left[\frac{-\alpha_{c} \cdot F}{R \cdot T} \cdot\left(V_{A}-\phi_{m}-U_{e q}\right)\right]$

271 where $\varepsilon_{\mathcal{v}}^{C L}$ is the catalyst layer porosity, $i_{0, c}\left(\mathrm{~A} \mathrm{~m}^{-2}\right)$ is the reference exchange current density

272 for the cathode, $C_{O_{2}}^{r e f}\left(\mathrm{~mol} \mathrm{~m}^{-3}\right)$ is the reference oxygen concentration in the catalyst layer, $\alpha_{c}$

273 is the cathodic transfer coefficient, $V_{A}(\mathrm{~V})$ is the applied cell voltage, $U_{e q}(\mathrm{~V})$ is the standard equilibrium potential of the oxygen reduction reaction, and $\phi_{m}(\mathrm{~V})$ is the membrane potential.

275 The effect of the catalyst morphology is taken into account by the active catalyst surface area 276 per unit volume of agglomerates, $a_{P t}^{a g g}\left(\mathrm{~m}^{2} \mathrm{~m}^{-3}\right)$, which is defined as: 
$277 \quad a_{P t}^{a g g}=\frac{a_{P t} \cdot m_{P t}}{t_{C L} \cdot\left(1-\varepsilon_{v}^{C L}\right)}$

278 where $m_{P t}\left(\mathrm{~g}_{\mathrm{Pt}} \mathrm{m}^{-2}\right)$ is the platinum loading, $t_{C L}(\mathrm{~m})$ is the catalyst layer thickness, and $a_{P t}\left(\mathrm{~m}^{2}\right.$

$\left.279 \mathrm{~g}^{-1}\right)$ is the surface area per unit mass of platinum particle, which is estimated from the empirical

280 correlation for platinum supported catalyst [63]:

$281 \quad \alpha_{P t}=227.79 \cdot(P t \mid C)^{3}-158.57 \cdot(P t \mid C)^{2}-201.53 \cdot(P t \mid C)+159.5$

282 where $P t \mid C$ is the platinum to carbon ratio in a catalyst agglomerate. The calculated value of $283 a_{P t}$ is $95.6 \mathrm{~m}^{2} \mathrm{~g}^{-1}$.

284 The relation between $P t \mid C, m_{p t}$, and $t_{C L}$ is given by [35]:

$285 \quad \varepsilon_{s}^{c l}=\left(\frac{1}{\rho_{P t}}+\frac{1-P t \mid C}{\rho_{P t} \cdot P t \mid C}\right) \frac{m_{P t}}{t_{c l}}$

286 The effectiveness factor, $\xi$, for a spherical agglomerate in Eq. (21) is given by:

287

$\xi=\frac{1}{\varphi} \cdot \frac{3 \cdot \varphi \cdot \operatorname{coth}(3 \cdot \varphi)-1}{3 \cdot \varphi}$

where the Thiele modulus, $\varphi$, is equal to [35]:

289

$\varphi=\frac{r_{a g g}}{3} \cdot \sqrt{\frac{k_{t}}{\left(1-\varepsilon_{v}^{C L}\right) \cdot D_{O_{2, \text { eff }}}^{N}}}$

The use of the Thiele modulus for the calculation of the effectiveness factor of spherical agglomerates is based on the assumption that the interior pore space of agglomerates is void of liquid water. Although this does not fully reflect the actual condition within the catalyst agglomerates, the use of the Thiele modulus for PEMFC simulations is still common practice, with models showing remarkable agreement with experimental data $[39,51,94]$. Accounting for the presence of liquid water in the interior pore space would lead to some quantitative changes in the results, i.e., a reduction in the predicted overall cell performance. However, the general trend in performance improvement with respect to branching generations should 
remain unchanged. This is because the improvement in fuel cell performance stems primarily

299 from better distribution of reactant gas across the catalyst layer, instead of within the catalyst

300 agglomerates. The effective oxygen diffusivity inside the agglomerates can also be expressed

301 as a function of the pore volume fraction $\left(\varepsilon_{N}^{a g g}\right)$ and the tortuosity $\left(\tau_{a g g}\right)$ via eqn. (28) [95]:

$302 \quad D_{O_{2}, \text { eff }}^{N}=D_{O_{2}}^{N} \cdot \frac{\varepsilon_{N}^{a g g}}{\tau_{\text {agg }}}$

303 The water film thickness is related to the liquid saturation level in the catalyst layer and it can

304 be estimated by $[35,53]$ :

$305 \quad \delta_{w}=\frac{\varepsilon_{v}^{C L} \cdot s}{a_{r}}$

306 The effective agglomerate surface area, $a_{r}\left(\mathrm{~m}^{2} \mathrm{~m}^{-3}\right)$, is defined as the outer surface area of the

307 agglomerates per unit volume of the catalyst layer, and is given by:

308

$a_{r}=\frac{3}{r_{a g g} \cdot\left(1-\varepsilon_{v}^{C L}\right)}$

309 where $r_{a g g}(\mathrm{~m})$ is the catalyst agglomerate radius. The effectiveness factor of the hydrogen oxidation reaction (HOR) is set to 1.0 , because hydrogen dissolves rapidly into the electrolyte,

311 and the Butler-Volmer equation is used to describe the HOR kinetics [96]:

$312 R_{H_{2}}=a_{P t}^{a g g} \cdot i_{0, a} \cdot\left(\frac{P_{H_{2}}}{C_{H_{2}}^{r e f} \cdot H_{H_{2}}}\right)^{0.5} \cdot\left[\exp \left(\frac{-\left(1-\alpha_{a}\right) \cdot F \cdot \eta_{a}}{R \cdot T}\right)-\exp \left(\frac{\alpha_{a} \cdot F \cdot \eta_{a}}{R \cdot T}\right)\right]$

313 where $i_{0, a}\left(\mathrm{~A} \mathrm{~m}^{-2}\right)$ is the reference exchange current density for the anode, $P_{H 2}(\mathrm{~Pa})$ is the partial

314 pressure of hydrogen, $C_{H_{2}}^{r e f}\left(\mathrm{~mol} \mathrm{~m}^{-3}\right)$ is the reference hydrogen concentration in the catalyst

315 layer, $H_{H 2}\left(\mathrm{~atm} \mathrm{~m} \mathrm{~mol}^{-1}\right)$ is Henry's constant of hydrogen between air and electrolyte, $\alpha_{a}$ is

316 the anodic transfer coefficient, and $\eta_{a}$ is the anodic overpotential. 
318 The rate of water phase change $\left(\mathrm{mol} \mathrm{m}^{-3} \mathrm{~s}^{-1}\right)$ in the porous medium is expressed by [53]:

$319 \quad S_{\text {phase }}= \begin{cases}k_{c} \cdot \frac{\varepsilon_{i}^{v} \cdot(1-s) \cdot y_{v}}{R \cdot T} \cdot\left(y_{v} \cdot P-P_{v}^{s a t}\right) & y_{v} \cdot P \geq P_{v}^{s a t} \\ k_{v} \cdot \frac{\varepsilon_{i}^{v} \cdot s \cdot \rho_{w}}{M_{w}} \cdot\left(y_{v} \cdot P-P_{v}^{s a t}\right) & y_{v} \cdot P<P_{v}^{s a t}\end{cases}$

320 where $y_{v}$ is the mole fraction of liquid water, $\rho_{w}\left(\mathrm{~kg} \mathrm{~m}^{-3}\right)$ is the density of liquid water, $M_{w}(\mathrm{~kg}$

$\left.321 \mathrm{~mol}^{-1}\right)$ is the molar weight of water, $P(\mathrm{~Pa})$ is the total pressure, $k_{c}$ and $k_{v}\left(\mathrm{~s}^{-1}\right)$ are the

322 condensation and evaporation rate constant, respectively. The vapor saturation pressure, $P_{v}^{\text {sat }}$

$323(\mathrm{~Pa})$, is calculated using the Antoine equation [97]:

$P_{v}^{s a t}=\exp \left[16.3872-\frac{3885.7}{(T-273.15)+230.17}\right]$

325 Boundary conditions used in this model are outlined in supplementary information.

326

\section{3. Simulation procedure}

328 3.1. Inlet fractal flow-field

329 The domain described in Fig. 2 was modeled using the finite element solver COMSOL v.5.

330 Simulations were conducted using a DELL Precision T3500 workstation with 24 GB of RAM and a 3.2 GHz Intel Xeon processor; each simulation lasted approximately 60 seconds. The gas diffusion and catalyst layers were described by the parameters listed in Table 2. A series of

333 parametric sweeps over the number of branching generations and GDL thickness was used to

334 determine the effect of the fractal flow-field architecture on the overall fuel cell performance.

335 The stoichiometry ratio of 2, a common value invoked in commercial fuel cell systems, was used for both cathode and anode, and the simulation was performed at an operating voltage of

$3370.4 \mathrm{~V}$ throughout, unless otherwise stated. Such operating conditions were chosen to represent 
a regime of operation expected to be limited by reactant access to the electrode, so that the advantages of the fractal flow-field could be expected to become important.

340 The main solution variables we are solving for in this simulation include gas velocity $\left(u_{g}\right)$, gas

341 pressure $(P)$, capillary pressure $\left(P_{c}\right)$, mole $\left(x_{i}\right)$ and mass $\left(w_{i}\right)$ fraction of individual gas species,

342 saturation $(s)$, solid $\left(\phi_{s}\right)$, and electrolyte $\left(\phi_{N}\right)$ phase potentials, rate of water phase change $\left(S_{\text {phase }}\right)$,

343 and reaction rate constant $\left(k_{t}\right)$.

344 3.2. Optimization of the microstructure

345 Parameters optimized with respect to power density $\left(P_{D}\right)$ and platinum utilization $\left(U_{P t}\right)$ were

346 obtained using objective functions proposed in previous studies [35, 98]. The objective

347 function for $P_{D}$ optimization aims to maximize the current density within the cathode catalyst

348 layer, and is defined as follows [98]:

349

$4 F V \cdot \max \left[\int_{\left(L-t_{C L}\right)}^{L} R_{O_{2}} d x\right]$

350 with: $0.12<\varepsilon_{s}^{C L}<1 ; 0.12<\varepsilon_{N}^{C L}<1 ; 0.25<\varepsilon_{v}^{C L}<1 ; 0.01<m_{P t}<1.0$; and $0.10<P t \mid C<0.90$.

351 The objective function for $U_{P t}$ optimization seeks to achieve high power density at low 352 platinum loading, and is expressed as follows [35]:

353 $4 F V \cdot \max \left[\frac{\int_{\left(L-t_{C L}\right)}^{L} R_{O_{2}} d x}{m_{P t}}\right]$

354 with the same constraints, as well as: $P_{D}>0.20 \frac{\mathrm{W}}{\mathrm{cm}^{2}}$.

355 The constraints on volume fractions ensure proper percolation in each phase (solid, ionomer, 356 gas). The constraint on minimum power density ensures that the microstructure can generate 
sufficient power density, while keeping the platinum loading low. Parameters not listed under

358 Eqs. (34) and (35), such as $r_{a g g}, \delta_{a g g}, \delta_{G D L}$, and $\varepsilon_{v}{ }^{G D L}$, were kept constant during optimization.

\section{Simulation results and discussion}

361 4.1. Effect of the number of branching generations on fuel cell performance

362 Increasing the number of branching generations, $N$, has two effects on the resultant concentration distribution in the porous medium. Firstly, with each additional generation, the distance between adjacent gas outlets is reduced, leading to an increasingly uniform boundary condition along the flow-field | GDL interface. Secondly, each subsequent generation increases

366 the total cross-sectional area of the outlets of the fractal inlet channels, thereby lowering the velocity of the reactant gas and, ultimately, allowing the convective flux at a channel outlet to approach the diffusive flux in the GDL.

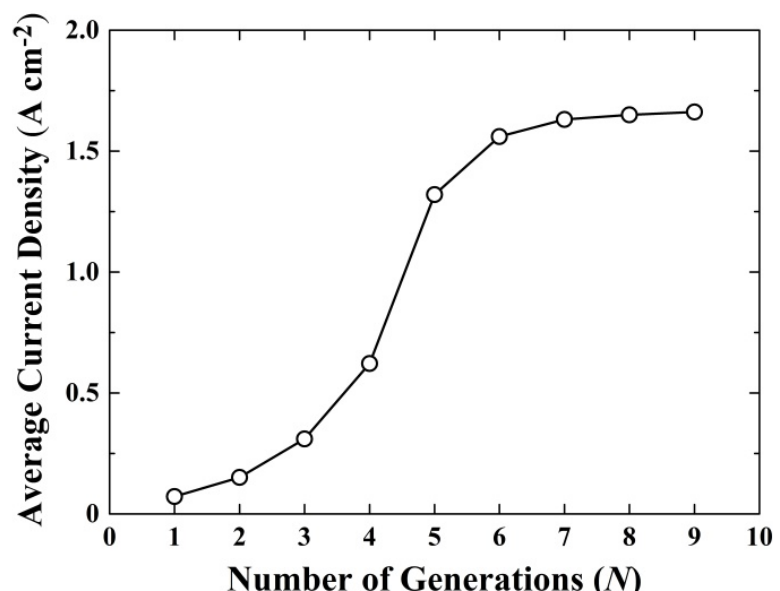

Fig. 5. Change in average current density with respect to the number of generations, $N$.

371 Simulation results were obtained for $100 \% \mathrm{RH}$.

372 Fig. 5 illustrates the performance of the lung-inspired flow-field based PEMFC as a function

373 of the number of generations (stoichiometry ratio of 2 in anode and cathode, $0.4 \mathrm{~V}$ operating 374 voltage, see section 3.1). At low generation levels $(N=1$ to 4$)$, the spacing between adjacent 375 distributor inlets is large ( $>$ GDL thickness) and the flow exiting the final generation is 
convection dominated (Pé > 1; Table 4). Therefore, only sub-sections of the active area directly

377 in the projection of the inlet are exposed to an appreciable amount of oxygen for reaction [20].

378 This leads to a highly non-uniform gas distribution across the plane of the catalyst layer and

379 low fuel cell performance.

380 A sharp increase in fuel cell performance occurs between $N=3$ and $N=6$ generations, as the 381 convective flux becomes equal to the diffusion flux at the exits for $N \sim 6$ (Pé $\sim 1$; Table 4), and

382 the spacing between inlets is sufficiently small to engender more uniform concentration 383 profiles at the GDL | CL interface.

384 At higher generations $(N \geq 8)$, the spacing between adjacent inlets becomes very small $(<100$ $385 \mu \mathrm{m})$ and diffusion takes over as the dominant transport mechanism in the final generation and 386 GDL (Pé < 1; Table 4). The resultant concentration profile at the catalyst layer interface is essentially completely uniform. As a result, a plateau in fuel cell performance is observed and additional generations (higher $N$ ) provide little benefit. Table 4 summarizes key geometric parameters for the simulation conducted in this study.

390 To validate the model, the theoretical results were compared to experimental results obtained at $100 \% \mathrm{RH}$ for $N=3$ and 4 , and $50 \% \mathrm{RH}$ for $N=5$. The current densities obtained at $0.4 \mathrm{~V}$ for $N=3,4$, and 5 were $0.64,0.76$, and $1.10 \mathrm{~A} \mathrm{~cm}^{-2}$, which correspond to a deviation of $\sim 52 \%$, $19 \%$, and $20 \%$, respectively [20]. The discrepancy between experimental and simulation results

394 for $N=3$ may have arisen from the 2D approximation, assuming uniform removal of unreacted reactant and product via fractal outlet channels. Despite this approximation, the deviation for $N=4$ and 5 from the theoretical results is small, which indicates that the simplified model provides accurate results in these situations, where more uniformity is envisioned. Hence, this simplified model can be used for the optimization of the thickness of the GDL and the cathode catalyst layer (CCL) microstructure. 
402 Summary of fractal flow-field simulations with standard composition cathode catalyst layer.

\begin{tabular}{lllll}
\hline$N$ & Number of outlets & Outlet spacing $(\mu \mathrm{m})$ & Outlet width $(\mu \mathrm{m})$ & Pé \\
\hline 3 & 64 & 4000 & 992 & 3.89 \\
4 & 256 & 1800 & 625 & 2.45 \\
5 & 1024 & 823 & 394 & 1.54 \\
6 & 4096 & 378 & 248 & 0.97 \\
7 & 16384 & 170 & 156 & 0.61 \\
8 & 65536 & 74.7 & 98.0 & 0.39 \\
9 & 262144 & 30.9 & 62.0 & 0.24 \\
\hline
\end{tabular}

403

4.2. Effect of the number of branching generations on GDL thickness.

404 The incorporation of a fractal flow-field to homogenize reactant concentration at the catalyst 405 layer GDL interface makes the GDL partially redundant, since they serve the same purpose.

406 Therefore, the GDL does not need to be as thick to provide the same degree of homogenization.

407 By reducing its thickness, additional concentration losses (resulting from the concentration 408 gradient across the GDL) can be avoided. As a result, utilizing a thinner GDL would provide a 409 higher concentration of reactant gas to the catalyst layer, further enhancing fuel cell 410 performance.

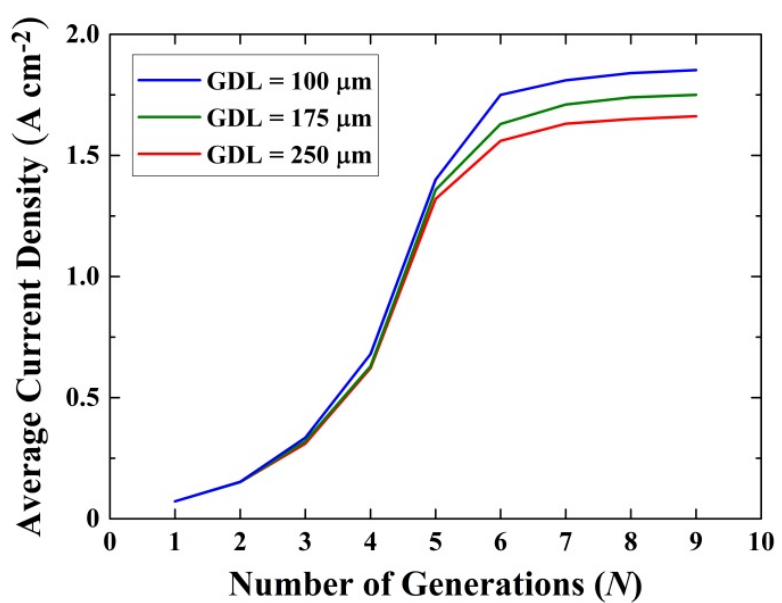

412 Fig. 6. Effect of GDL thickness on fuel cell performance. Simulation results were obtained for $413 \quad 100 \%$ RH.

414 A similar trend in fuel cell performance is observed up to $N=5$ generations for different GDL

415 thicknesses (Fig. 6). At these low generations, a decrease in GDL thickness merely exacerbates 
416 the variation in current density across the GDL | CL interface and does not enhance the fuel

417 cell performance. The increased local current density in the region adjacent to the inlet is offset

418 by a sharp decline in local current density under the land and outlet channels, due to diminished

419 transverse reactant transport in thinner GDLs [99-101] (Fig. 7 (a)).

420 At higher generations $(N \geq 5)$, an improvement in fuel cell performance is observed, as reactant

421 mass transport is facilitated by increasing the reactant concentration gradient across the catalyst

422 layer. This result is consistent with previous reports in the literature demonstrating an increase

423 in fuel cell performance via the utilization of thinner GDLs [32, 99, 102, 103], due to enhanced

424 mass transport. It is important to note that transport in the GDL is not limiting for $\mathrm{N}<5$, but

425 GDL thickness plays a role between $N=5$ and 6 , as the effective reaction rate within the

426 catalyst layer has then sufficiently increased such that the GDL plays a role in adding transport

427 resistance, if it is too thick.

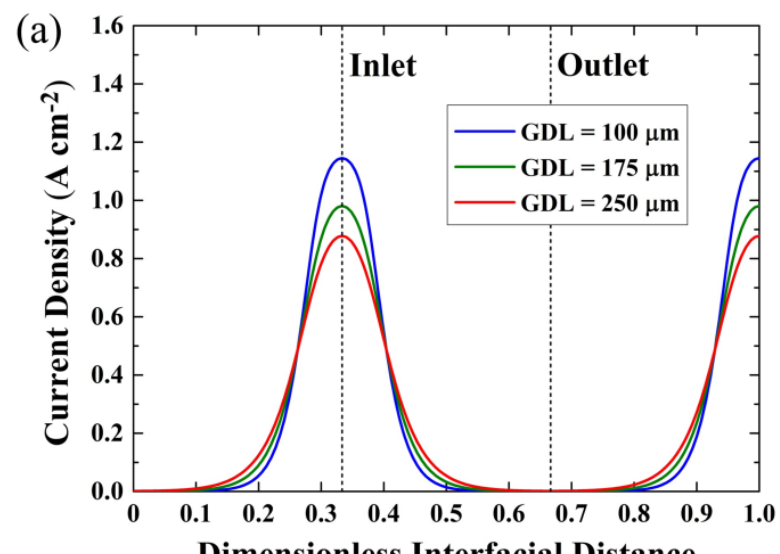

Dimensionless Interfacial Distance

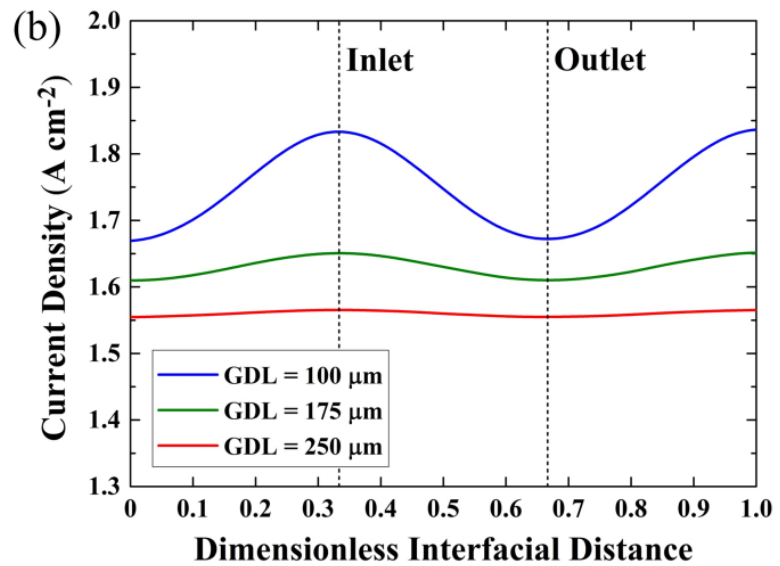


429 Fig. 7. Effect of gas diffusion layer thickness on local cell current density for (a) $N=3$ and (b)

$430 N=6$ (inlet positions at $x \sim 0.33$ and 1 ; outlet positions at $x \sim 0$ and 0.67 ). Simulation results

431 were obtained for $100 \%$ RH. This Figure was rotated clockwise by $90^{\circ}$ for ease of visualization.

432 Additionally, thinner GDLs enhance local current density as a direct consequence of higher 433 oxygen concentration across the catalyst layer (Fig. 7 (b)). This observation is in slight contrast 434 with previous reports exhibiting a small drop in current density under the land and outlet 435 channels with thinner GDLs as a result of reduced lateral mass transport [99-101]. However, 436 the reported aggravated reactant depletion near the outlet channels with thinner GDLs is circumvented for higher generation $(N \geq 5)$ fractal flow-fields due to their shorter path length between inlet and outlet channels, which subjects the entire catalyst layer to higher reactant concentration and current density. The reduction in lateral mass transport with thinner GDLs

440 is not completely attenuated, though, as suggested by the suppressed improvement in current 441 density in areas adjacent to the outlet channels, compared to the inlet channels (Fig. 7 (b)).

442 Besides the improved fuel cell performance using a thinner GDL, an additional benefit of up 443 to $\sim 25 \%$ reduction in cell thickness and volumetric power density of the stack is realized, given a commercial cell thickness of $1.2 \mathrm{~mm}$.

\section{Table 5}

446 Results of microstructure optimization to maximize power density $\left(P_{D}\right)$ and platinum utilization $\left(U_{P t}\right)$ in the cathode catalyst layer.

\begin{tabular}{llllllll}
\hline Cathode catalyst & $m_{P t}\left(\mathrm{mg}_{\mathrm{Pt}} \mathrm{cm}^{-2}\right)$ & $P t \mid C$ & $\varepsilon_{v}^{C L}$ & $\varepsilon_{s}^{C L}$ & $\varepsilon_{N}{ }^{C L}$ & $\varepsilon_{N, a g g}$ & $t_{C L}(\mu \mathrm{m})$ \\
\hline Base design & 0.40 & 0.28 & 0.50 & 0.13 & 0.37 & 0.66 & 40 \\
$P_{D}$ optimized & 0.18 & 0.29 & 0.25 & 0.13 & 0.62 & 0.78 & 18 \\
$U_{P t}$ optimized & 0.01 & 0.27 & 0.25 & 0.14 & 0.61 & 0.77 & 1.0 \\
\hline
\end{tabular}
in determining the performance of PEMFCs. From the perspective of fuel cell performance and cost, generating sufficient power density, while lowering the catalyst loading and improving 
catalyst utilization, are key criteria to design an efficient catalyst layer. Here, fractal flow-fields are coupled with the CCL microstructures, which were independently optimized with respect to maximum platinum utilization $\left(U_{P t}\right)$ and power density $\left(P_{D}\right)$ under the assumption of uniform reactant concentration profile across the flow-field | GDL interface, as proposed by Marquis and Coppens $[35,98]$ (Table 5) and presented in section 3.2. While the ionomer fraction in the $P_{D}$ and $U_{P t}$ optimized CCL are higher than values typically reported in the literature, the higher Nafion content is accounted for by a much thinner catalyst layer. Also, in the case of a $U_{P t}$ optimized CCL, the lower reaction rate (due to ultra-low platinum loading) diminishes the effect of diffusion limitations and, therefore, allows for a higher ionomer fraction in the catalyst layer. The radius of the catalyst agglomerates is known to significantly dictate the performance of the CCL. While not included as a design variable in this work, a value of $100 \mathrm{~nm}$ is chosen to minimise any diffusion limitations occurring within the agglomerates themselves [35].

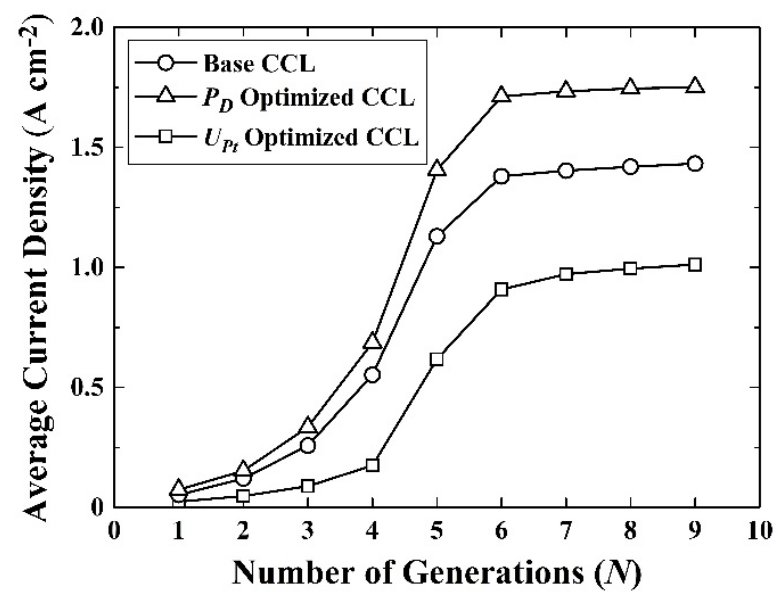

Fig. 8. Simulation results showing the effect of the number of fractal branching generations on average cell current density for the base and optimized CCL (cathode catalyst layer) microstructures. The operating conditions are $S_{\text {Anode }}=1.5, S_{\text {Cathode }}=2, r_{\text {agg }}=100 \mathrm{~nm}$, and $100 \%$ 468 RH.

Fig. 8 compares the fractal flow-field performance of $U_{P t}$ and $P_{D}$ optimized CCL microstructures to the base design at different generations $N$. The trend in fuel cell performance improvement is similar to previous results, differing only in the magnitude of change in the average current density. 
473 The $P_{D}$ optimized CCL microstructure displays the highest average current density at $N \geq 5$, 474 despite its lower platinum loading than the base (non-optimized microstructure) CCL (Table

475 5). Its optimized microstructure alleviates the diffusion limitations inside the catalyst layer and 476 agglomerates, resulting in a $\sim 20 \%$ increase in average current density (Fig. 8). With less 477 branching generations $(N<5)$, the $P_{D}$ optimized CCL microstructure performance 478 improvement over the base microstructure is lower, indicating that non-uniform gas 479 distribution limits mass transport towards the catalyst layer and, hereby, catalyst utilization. A 480 significant portion of the catalyst layer adjacent to the outlet channels is oxygen-depleted, and, 481 thus, the optimized catalyst layer in these regions does not result in higher current density.

482 On the contrary, the $U_{P t}$ optimized CCL exhibits the lowest average current density due to its 483 low platinum loading ( $\sim 40$ times lower than the base design) resulting in a low reaction rate 484 [35]. Despite its low intrinsic performance, the $U_{P t}$ optimized CCL as a whole surpasses the 485 DoE target for platinum utilization of $\sim 8 \mathrm{~kW} / \mathrm{g}_{\mathrm{Pt}}[104]$ at $N=4$ generations, and plateaus at 486 approximately $36 \mathrm{~kW} / \mathrm{g}_{\mathrm{Pt}}$ at $N=6$ generations (Fig. 9). This finding suggests that either the 487 platinum loading or the number of cells in the stack could potentially be reduced by $\sim 75 \%$, 488 allowing for a significant cost reduction in the electrocatalyst and fuel cell components. The 489 ultra-low platinum loading of a $U_{P t}$ optimized CCL allows exposure of appreciable oxygen 490 concentration to platinum catalyst along the radius of the agglomerates, enhancing platinum 491 utilization. Its significantly thinner catalyst layer (Table 5) also facilitates gas diffusion and 492 proton conduction across the CCL, improving mass transport across the CCL and subsequent 493 platinum utilization. 


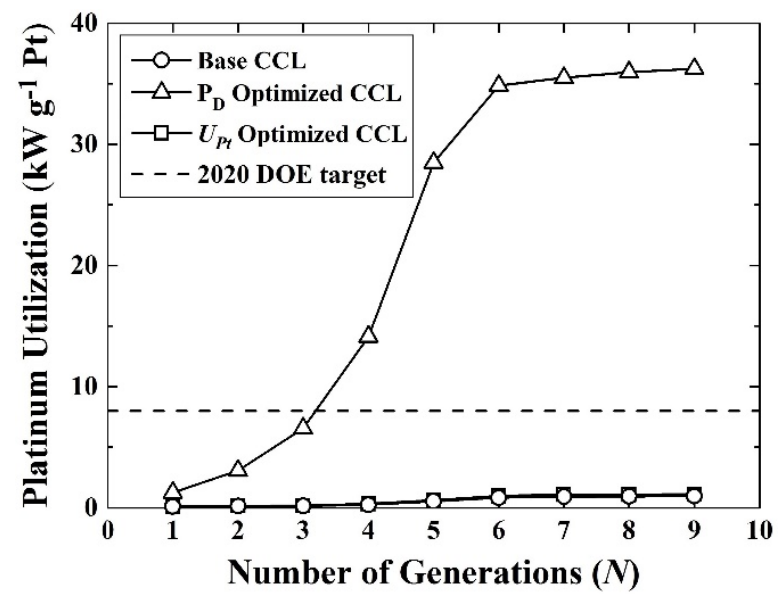

494

Fig. 9. Simulation results showing the effect of the number of fractal branching generations on

495 platinum utilization for the base and optimized CCL microstructures. The operating conditions

497 are $\mathrm{S}_{\text {Anode }}=1.5, \mathrm{~S}_{\text {Cathode }}=2, \mathrm{r}_{\text {agg }}=100 \mathrm{~nm}$, and $100 \% \mathrm{RH}$.

498 The base and $P_{D}$ optimized cathode CL designs demonstrate substandard platinum utilization

499 for all generations, since metal nanoparticles situated towards the center of an agglomerate are

500 subjected to extremely low oxygen concentrations, due to significant diffusion limitations

501 arising from surplus catalyst loading. A small improvement in platinum utilization with respect

502 to the number of generations indicates that platinum utilization is not limited by reactant

503 distribution across the electrode, but by reactant transport within the catalyst agglomerate.

504 Collectively, these results show that proper design of catalyst layer microstructure and platinum

505 loading, factors that predominantly determine oxygen concentration profile within an

506 agglomerate, is indispensable to realize enhanced platinum utilization from a uniform gas

507 distribution.

508

509 5. Conclusions

510 A finite-element model of a lung-inspired flow-field based PEMFC was presented. This model

511 was used to determine the effect of the number of branching generations, $N$, on the required

512 thickness of the GDL and fuel cell performance. 
513 Introduction of a fractal flow-field to homogenize reactant concentration at the flow-field

514 GDL interface allows for a thinner GDL to be used. Fuel cell performance is enhanced further

515 with a thinner GDL, as a result of higher oxygen concentration across the catalyst layer for a

516 higher number of branching generations, $N$. However, the reduction in lateral mass transport

517 with thinner GDLs only leads to minimal improvement in fuel cell performance for lower

518 numbers of generations $(N \leq 5)$.

519 The finite-element model of the lung-inspired flow-field based PEMFC was coupled with

520 cathode catalyst layer (CCL) microstructures optimized with respect to platinum utilization

$521\left(U_{P t}\right)$ and power density $\left(P_{D}\right)$. Despite its lower platinum loading, the $P_{D}$ optimized CCL yields

522 a higher average current density than the base design, because of a microstructure that

523 facilitates diffusion within the catalyst layer. In the case of a $U_{P t}$ optimized CCL, the ultra-low

524 platinum loading significantly lowers the reaction rate, resulting in a reduced fuel cell current

525 density.

526 In terms of platinum utilization, the $U_{P t}$ optimized CCL surpasses the 2020 DoE target for

527 platinum utilization of $\sim 8 \mathrm{~kW} / \mathrm{g}_{\mathrm{Pt}}$ for $N=4$ generations, and achieves a value of $\sim 36 \mathrm{~kW} / \mathrm{g}_{\mathrm{Pt}}$

528 when $N=6$. The base and $P_{D}$ optimized microstructures demonstrate extremely low platinum

529 utilization, due to substantial oxygen deprivation towards the center of the catalyst

530 agglomerates from surplus platinum loading. A multi-objective optimization involving

531 platinum loading and power density may be beneficial to evaluate the trade-off between the

532 objectives for the design of efficient and robust fuel cell catalyst layers.

533 An important aspect of PEMFC operation using a fractal flow-field is how liquid water is 534 handled in the gas channels. Water transport across a channel cannot be investigated on a 2D 535 domain; a 3D model should be developed to substantiate the effect of channel geometries on 536 water removal, despite the high computational cost. Fortunately, however, this may not be 537 necessary: By integrating the capillary-based water management strategy recently developed 
538 in our group $[105,106]$ with the fractal flow-fields, flooding in the cathode should be pre539 empted, which would lead to robust and reliable fuel cell performance, irrespective of the

540 operating conditions. Therefore, the advantages of a uniform gas flow could be preserved also

541 at higher branching ratios, $N$.

542 To further improve the model presented in this manuscript, the following aspects have to be

543 implemented: $i$ ) percolation theory instead of the Bruggeman equation to account for reduced

544 connectivity of the pores by using an adaptation of recent pore network modeling approaches

545 developed by our group in collaboration with ECUST.[107, 108] The percolation theory

546 ensures that the effective diffusivity is zero below the percolation threshold, when a connected

547 gas diffusion network ceases to exist. [53, 109]; ii) temperature effects to monitor the changes

548 in liquid water content in the fuel cell under different experimental conditions [110-113]; and

549 iii) local resistance in the form of an oxygen transport barrier to capture transport losses at the 550 surface of the catalyst layer microstructure [114-118].

552 Declaration of interest

553 Declarations of interest: none

\section{Acknowledgement}

556 The authors wish to thank the US National Science Foundation Fuel Cell IGERT at Rensselaer

557 (grant number DGE-0504361) for supporting the start of this work. Continued research at UCL

558 was made possible thanks to financial support from an EPSRC "Frontier Engineering" Award (grant number EP/K038656/1) and a UCL Faculty of Engineering Sciences Dean’s Scholarship. 
$A \quad$ active area, $\mathrm{m}^{2}$

$A_{N} \quad$ cross-sectional area of a single outlet at the $\mathrm{N}^{\text {th }}$ generation, $\mathrm{m}^{2}$

$a_{r} \quad$ effective agglomerate surface area, $\mathrm{m}^{2} \mathrm{~m}^{-3}$

$a_{P t} \quad$ effective catalyst surface area, $\mathrm{m}^{2} \mathrm{~g}^{-1}$

C total gas concentration, $\mathrm{mol} \mathrm{m}^{-3}$

$C_{f} \quad$ fixed charge site concentration in membrane, $\mathrm{mol} \mathrm{m}^{-3}$

$C_{H 2}^{r e f} \quad$ reference concentration of hydrogen, $\mathrm{mol} \mathrm{m}^{-3}$

$\mathrm{CO}_{\mathrm{O} 2}$ concentration of oxygen in catalyst layer, $\mathrm{mol} \mathrm{m} \mathrm{m}^{-3}$

$C_{O 2}^{r e f} \quad$ reference concentration of oxygen, $\mathrm{mol} \mathrm{m}^{-3}$

$C_{O 2}^{a i r} \quad$ concentration of oxygen in inlet air, $\mathrm{mol} \mathrm{m}^{-3}$

$C_{v}^{g} \quad$ concentration of vapor, $\mathrm{mol} \mathrm{m}^{-3}$

$C_{v}^{g, a i r} \quad$ concentration of water vapor in inlet air, $\mathrm{mol} \mathrm{m}^{-3}$

$C_{w}^{N} \quad$ water concentration in membrane, $\mathrm{mol} \mathrm{m}^{-3}$

$D \quad$ fractal dimension

$D \quad$ diffusivity $\left(\mathrm{m}^{2} \mathrm{~s}^{-1}\right)$

$D_{c} \quad$ capillary diffusion coefficient, $\mathrm{m}^{2} \mathrm{~s}^{-1}$

$D_{i j} \quad$ element of the Maxwell-Stefan diffusion coefficient matrix, $\mathrm{m}^{2} \mathrm{~s}^{-1}$

$D_{O 2}^{N} \quad$ oxygen diffusivity in Nafion, $\mathrm{m}^{2} \mathrm{~s}^{-1}$

$D_{O 2, N}^{e f f} \quad$ effective oxygen diffusivity in Nafion, $\mathrm{m}^{2} \mathrm{~s}^{-1}$

$D_{O 2}^{w} \quad$ oxygen diffusivity in water, $\mathrm{m}^{2} \mathrm{~s}^{-1}$

$D_{w}^{N} \quad$ diffusivity of water in Nafion, $\mathrm{m}^{2} \mathrm{~s}^{-1}$

F $\quad$ Faraday's constant, $96500 \mathrm{C} \mathrm{mol}^{-1}$ 
$H \quad$ Henry's constant, atm $\mathrm{m}^{3} \mathrm{~mol}^{-1}$

$i_{N} \quad$ electrolyte current density, $\mathrm{A} \mathrm{m}^{-2}$

$i_{d} \quad$ current density, $\mathrm{A} \mathrm{m}^{-2}$

$i_{s} \quad$ electronic current density, $\mathrm{A} \mathrm{m}^{-2}$

$i_{0} \quad$ exchange current density, $\mathrm{A} \mathrm{m}^{-2}$

$k_{c} \quad$ condensation rate constant, $\mathrm{s}^{-1}$

$k_{p} \quad$ electrode permeability, $\mathrm{m}^{2}$

$k_{v} \quad$ evaporation rate constant, atm ${ }^{-1} \mathrm{~s}^{-1}$

$k_{t} \quad$ reaction rate constant, $\mathrm{s}^{-1}$

$K_{w} \quad$ water permeability, $\mathrm{m}^{2}$

$K_{w, 0} \quad$ water permeability at $100 \%$ saturation, $\mathrm{m}^{2}$

$L \quad$ width of fractal outlet at the final generation, $\mathrm{m}$

$m_{p t} \quad$ platinum loading per unit area of catalyst layer, $\mathrm{g}_{\mathrm{Pt}} \mathrm{m}^{-2}$

$M_{i} \quad$ molecular weight, $\mathrm{kg} \mathrm{mol}{ }^{-1}$

$m \quad$ electro-osmotic drag coefficient

$N \quad$ number of fractal generations

$N_{i}^{g} \quad$ flux of gaseous species $i, \mathrm{~mol} \mathrm{~m}^{-2} \mathrm{~s}^{-1}$

$N_{v}^{g} \quad$ flux of vapor, $\mathrm{mol} \mathrm{m} \mathrm{m}^{-2} \mathrm{~s}^{-1}$

$N_{w} \quad$ flux of liquid water, $\mathrm{mol} \mathrm{m}^{-2} \mathrm{~s}^{-1}$

$N_{w}^{g} \quad$ flux of water vapor, $\mathrm{mol} \mathrm{m}^{-2} \mathrm{~s}^{-1}$

$N_{w}^{N} \quad$ flux of liquid water in membrane, $\mathrm{mol} \mathrm{m} \mathrm{m}^{-2} \mathrm{~s}^{-1}$

$P \quad$ total pressure, $\mathrm{Pa}$

$P_{c} \quad$ capillary pressure, $\mathrm{Pa}$

$P_{D} \quad$ power density, $\mathrm{W} \mathrm{cm}^{-2}$ 
$P_{g} \quad$ gas pressure, $\mathrm{Pa}$

$P_{i} \quad$ partial pressure, $\mathrm{Pa}$

$P_{l} \quad$ liquid pressure, $\mathrm{Pa}$

$P^{\text {sat }} \quad$ saturation pressure, $\mathrm{Pa}$

$U_{P t} \quad$ platinum utilization, $\mathrm{kW} \mathrm{g}^{-1} \mathrm{Pt}$

$P t \mid C \quad$ mass percentage of platinum catalyst on carbon black, $\mathrm{kg} \mathrm{Pt} /(\mathrm{kg} \mathrm{C}+\mathrm{kg} \mathrm{Pt})$

$Q_{o} \quad$ volumetric flow rate of gas at the inlet, $\mathrm{m}^{3} \mathrm{~s}^{-1}$

ragg agglomerate radius, $\mathrm{m}$

$R \quad$ ideal gas constant, $8.314 \mathrm{~J} \mathrm{~mol}^{-1} \mathrm{~K}^{-1}$

$R_{i} \quad$ reaction rate, $\mathrm{mol} \mathrm{m}^{-3} \mathrm{~s}^{-1}$

$S_{\text {Anode }} \quad$ anode stoichiometry ratio, 2

$S_{\text {Cathode }}$ cathode stoichiometry ratio, 2

$S_{\text {phase }} \quad$ evaporation/condensation rate, $\mathrm{mol} \mathrm{m}^{-3} \mathrm{~s}^{-1}$

$s \quad$ liquid water saturation

$S \quad$ source term

$T \quad$ temperature, $\mathrm{K}$

$t_{C L} \quad$ catalyst layer thickness, $\mathrm{m}$

$t_{G D L} \quad$ gas diffusion layer thickness, $\mathrm{m}$

$t_{\text {mem }} \quad$ membrane thickness, $\mathrm{m}$

$u_{g} \quad$ gas phase velocity, $\mathrm{m} \mathrm{s}^{-1}$

$U_{e q} \quad$ standard equilibrium potential, $\mathrm{V}$

V voltage, $\mathrm{V}$

$V_{A} \quad$ operating voltage, $\mathrm{V}$

$W_{c, 1} \quad$ initial channel width, $\mathrm{m}$ 
mass fraction of species $i$

$x_{i} \quad$ mole fraction of species $i$

$y_{v} \quad$ mole fraction of liquid water

\section{Greek}

$\alpha \quad$ charge transfer coefficient

$a_{P t}^{a g g} \quad$ specific catalyst surface area, $\mathrm{m}^{2} \mathrm{~m}^{-3}$

$\delta_{N} \quad$ Nafion film thickness, $\mathrm{m}$

$\delta_{W} \quad$ water film thickness, $\mathrm{m}$

$\varepsilon_{N}^{a g g} \quad$ agglomerate-ionomer volume fraction, $\mathrm{m}^{3}$ ionomer $\mathrm{m}^{-3}$ agglomerate

$\varepsilon^{\nu} \quad$ void phase volume fraction

$\eta \quad$ overpotential, $\mathrm{V}$

$\mu \quad$ viscosity, $\mathrm{Pa} \mathrm{s}$

$\xi \quad$ effectiveness factor

$\rho \quad$ density, $\mathrm{kg} \mathrm{m}^{-3}$

$\sigma_{m} \quad$ ionic conductivity, $\mathrm{S} \mathrm{m}^{-1}$

$\sigma_{s} \quad$ electronic conductivity, $\mathrm{S} \mathrm{m}^{-1}$

$\tau \quad$ tortuosity

$\phi \quad$ potential, $\mathrm{V}$

$\varphi \quad$ Thiele modulus

$\phi_{N} \quad$ membrane phase potential, $\mathrm{V}$

\section{Superscripts and subscripts}

$0 \quad$ intrinsic

a anode 


\begin{tabular}{|c|c|}
\hline agg & agglomerate \\
\hline $\mathrm{c}$ & cathode \\
\hline CL & catalyst layer \\
\hline eff & effective \\
\hline eq & equilibrium \\
\hline $\mathrm{g}$ & gas \\
\hline GDL & gas diffusion layer \\
\hline $\mathrm{H}_{2}$ & hydrogen \\
\hline $\mathrm{i}$ & species $i$ \\
\hline $\mathrm{j}$ & species $j$ \\
\hline mem & membrane \\
\hline $\mathrm{N}$ & Nafion \\
\hline $\mathrm{N}_{2}$ & nitrogen \\
\hline $\mathrm{O}_{2}$ & oxygen \\
\hline $\mathrm{Pt}$ & platinum \\
\hline ref & reference \\
\hline s & solid phase \\
\hline $\mathrm{v}$ & void phase / vapor \\
\hline $\mathrm{W}$ & liquid water \\
\hline
\end{tabular}


1. Pollet, B.G., S.S. Kocha, and I. Staffell, Current status of automotive fuel cells for

2. Arvay, A., et al., Nature inspired flow field designs for proton exchange membrane fuel cell. International Journal of Hydrogen Energy, 2013. 38(9): p. 3717-3726.

3. Wu, H.-W., A review of recent development: Transport and performance modeling of PEM fuel cells. Applied Energy, 2016. 165: p. 81-106.

4. Wang, C., et al., The respective effect of under-rib convection and pressure drop of flow fields on the performance of PEM fuel cells. 2017. 7: p. 43447.

5. Wu, Y., et al., Effect of serpentine flow-field design on the water management of polymer electrolyte fuel cells: An in-operando neutron radiography study. Journal of Power Sources, 2018. 399: p. 254-263.

6. Trogadas, P., T.F. Fuller, and P. Strasser, Carbon as catalyst and support for electrochemical energy conversion. Carbon, 2014. 75: p. 5-42.

7. Taniguchi, A., et al., Analysis of electrocatalyst degradation in PEMFC caused by cell reversal during fuel starvation. Journal of Power Sources, 2004. 130(1): p. 42-49.

8. Schmittinger, W. and A. Vahidi, A review of the main parameters influencing long-term performance and durability of PEM fuel cells. Journal of Power Sources, 2008. 180(1): p. 1-14.

9. Narimani, M., J. DeVaal, and F. Golnaraghi, Hydrogen emission characterization for proton exchange membrane fuel cell during oxygen starvation - Part 1: Low oxygen concentration. International Journal of Hydrogen Energy, 2016. 41(8): p. 4843-4853.

10. Trogadas, P., et al., Hierarchically Structured Nanomaterials for Electrochemical Energy Conversion. Angewandte Chemie International Edition, 2016. 55(1): p. 122148.

11. Trogadas, P., J. Parrondo, and V. Ramani, Degradation Mitigation in Polymer Electrolyte Membranes Using Cerium Oxide as a Regenerative Free-Radical Scavenger. Electrochemical and Solid-State Letters, 2008. 11(7): p. B113-B116.

12. Trogadas, P., J. Parrondo, and V. Ramani, CeO2 Surface Oxygen Vacancy Concentration Governs in Situ Free Radical Scavenging Efficacy in Polymer Electrolytes. ACS Applied Materials \& Interfaces, 2012. 4(10): p. 5098-5102.

13. Kulkarni, N., et al., Effect of cell compression on the water dynamics of a polymer electrolyte fuel cell using in-plane and through-plane in-operando neutron radiography. Journal of Power Sources, 2019. 439: p. 227074.

14. Wawdee, P., et al., Water transport in a PEM fuel cell with slanted channel flow field plates. International Journal of Hydrogen Energy, 2015. 40(9): p. 3739-3748.

15. Kozakai, M., et al., Improving gas diffusivity with bi-porous flow-field in polymer electrolyte membrane fuel cells. International Journal of Hydrogen Energy, 2016. 41(30): p. 13180-13189.

16. Guo, N., M.C. Leu, and U.O. Koylu, Network based optimization model for pin-type flow field of polymer electrolyte membrane fuel cell. International Journal of Hydrogen Energy, 2013. 38(16): p. 6750-6761.

17. Guo, N., M.C. Leu, and U.O. Koylu, Bio-inspired flow field designs for polymer electrolyte membrane fuel cells. International Journal of Hydrogen Energy, 2014. 39(36): p. 21185-21195.

18. Hamilton, P.J. and B.G. Pollet, Polymer Electrolyte Membrane Fuel Cell (PEMFC) Flow Field Plate: Design, Materials and Characterisation. Fuel Cells, 2010. 10(4): p. 489509.

19. Whiteley, M., et al., A novel polymer electrolyte fuel cell flow-field: The through-plane array. Journal of Power Sources, 2019. 442: p. 227218.

20. Trogadas, P., et al., A lung-inspired approach to scalable and robust fuel cell design. Energy \& Environmental Science, 2018. 11(1): p. 136-143. 
21. Kjelstrup, S., et al., Nature-inspired energy-and material-efficient design of a polymer electrolyte membrane fuel cell. Energy \& Fuels, 2010. 24(9): p. 5097-5108.

22. Coppens, M.-O., A nature-inspired approach to reactor and catalysis engineering. Current Opinion in Chemical Engineering, 2012. 1(3): p. 281-289.

23. Ozden, A., et al., Designing, modeling and performance investigation of bio-inspired flow field based DMFCs. International Journal of Hydrogen Energy, 2017. 42(33): p. 21546-21558.

24. Vyatskikh, A., et al., Additive manufacturing of $3 D$ nano-architected metals. Nature Communications, 2018. 9(1): p. 593.

25. Luca, H., et al., Additive Manufacturing of Metal Structures at the Micrometer Scale. Advanced Materials, 2017. 29(17): p. 1604211.

26. Bourell, D.L., Perspectives on Additive Manufacturing. Annual Review of Materials Research, 2016. 46(1): p. 1-18.

27. Adilet, Z., et al., Additive Manufacturing: Unlocking the Evolution of Energy Materials. Advanced Science, 2017. 4(10): p. 1700187.

28. Ligon, S.C., et al., Polymers for 3D Printing and Customized Additive Manufacturing. Chemical Reviews, 2017. 117(15): p. 10212-10290.

29. Limjeerajarus, N. and P. Charoen-amornkitt, Effect of different flow field designs and number of channels on performance of a small PEFC. International Journal of Hydrogen Energy, 2015. 40(22): p. 7144-7158.

30. Lim, B.H., et al., Effects of flow field design on water management and reactant distribution in PEMFC: a review. Ionics, 2016. 22(3): p. 301-316.

31. Wang, C., et al., Effect of height/width-tapered flow fields on the cell performance of polymer electrolyte membrane fuel cells. International Journal of Hydrogen Energy, 2017. 42(36): p. 23107-23117.

32. Cindrella, L., et al., Gas diffusion layer for proton exchange membrane fuel cells-A review. Journal of Power Sources, 2009. 194(1): p. 146-160.

33. Park, S., J.-W. Lee, and B.N. Popov, A review of gas diffusion layer in PEM fuel cells: Materials and designs. International Journal of Hydrogen Energy, 2012. 37(7): p. 58505865.

34. Lee, J., et al., Investigating the effects of gas diffusion layer substrate thickness on polymer electrolyte membrane fuel cell performance via synchrotron X-ray radiography. Electrochimica Acta, 2017. 236: p. 161-170.

35. Marquis, J. and M.-O. Coppens, Achieving ultra-high platinum utilization via optimization of PEM fuel cell cathode catalyst layer microstructure. Chemical Engineering Science, 2013. 102: p. 151-162.

36. Berning, T. and N. Djilali, Three-dimensional computational analysis of transport phenomena in a PEM fuel cell-a parametric study. Journal of Power Sources, 2003. 124(2): p. 440-452.

37. Lum, K.W. and J.J. McGuirk, Three-dimensional model of a complete polymer electrolyte membrane fuel cell - model formulation, validation and parametric studies. Journal of Power Sources, 2005. 143(1): p. 103-124.

38. Du, C.Y., et al., Parametric study of a novel cathode catalyst layer in proton exchange membrane fuel cells. Journal of Power Sources, 2006. 160(1): p. 224-231.

39. Khajeh-Hosseini-Dalasm, N., et al., A parametric study of cathode catalyst layer structural parameters on the performance of a PEM fuel cell. International Journal of Hydrogen Energy, 2010. 35(6): p. 2417-2427.

40. Marr, C. and X. Li, Composition and performance modelling of catalyst layer in a proton exchange membrane fuel cell. Journal of Power Sources, 1999. 77(1): p. 17-27.

41. Tiedemann, W. and J. Newman, Maximum Effective Capacity in an Ohmically Limited Porous Electrode. Journal of The Electrochemical Society, 1975. 122(11): p. 14821485. 
42. You, L. and H. Liu, A parametric study of the cathode catalyst layer of PEM fuel cells using a pseudo-homogeneous model. International Journal of Hydrogen Energy, 2001. 26(9): p. 991-999.

43. Dobson, P., et al., Characterization of the PEM Fuel Cell Catalyst Layer Microstructure by Nonlinear Least-Squares Parameter Estimation. Journal of The Electrochemical Society, 2012. 159(5): p. B514-B523.

44. Ebrahimi, S., R. Roshandel, and K. Vijayaraghavan, Power density optimization of PEMFC cathode with non-uniform catalyst layer by Simplex method and numerical simulation. International Journal of Hydrogen Energy, 2016. 41(47): p. 22260-22273.

45. Ridge, S.J., et al., Oxygen Reduction in a Proton Exchange Membrane Test Cell. Journal of The Electrochemical Society, 1989. 136(7): p. 1902-1909.

46. Shah, A.A., et al., Transient non-isothermal model of a polymer electrolyte fuel cell. Journal of Power Sources, 2007. 163(2): p. 793-806.

47. Wang, G., P.P. Mukherjee, and C.-Y. Wang, Optimization of polymer electrolyte fuel cell cathode catalyst layers via direct numerical simulation modeling. Electrochimica Acta, 2007. 52(22): p. 6367-6377.

48. Xing, L., et al., Multi-variable optimisation of PEMFC cathodes based on surrogate modelling. International Journal of Hydrogen Energy, 2013. 38(33): p. 14295-14313.

49. Hu, G., et al., Optimization and parametric analysis of PEMFC based on an agglomerate model for catalyst layer. Journal of the Energy Institute, 2014. 87(2): p. 163-174.

50. Xing, L., et al., Numerical investigation of the optimal Nafion ${ }^{\circledR}$ ionomer content in cathode catalyst layer: An agglomerate two-phase flow modelling. International Journal of Hydrogen Energy, 2014. 39(17): p. 9087-9104.

51. Moein-Jahromi, M. and M.J. Kermani, Performance prediction of PEM fuel cell cathode catalyst layer using agglomerate model. International Journal of Hydrogen Energy, 2012. 37(23): p. 17954-17966.

52. Sun, W., B.A. Peppley, and K. Karan, An improved two-dimensional agglomerate cathode model to study the influence of catalyst layer structural parameters. Electrochimica acta, 2005. 50(16): p. 3359-3374.

53. Wang, X. and T.V. Nguyen, Modeling the Effects of Capillary Property of Porous Media on the Performance of the Cathode of a PEMFC. Journal of The Electrochemical Society, 2008. 155(11): p. B1085-B1092.

54. Molaeimanesh, G.R., M.A. Bamdezh, and M. Nazemian, Impact of catalyst layer morphology on the performance of PEM fuel cell cathode via lattice Boltzmann simulation. International Journal of Hydrogen Energy, 2018. 43(45): p. 20959-20975.

55. Zhan, N., W. Wu, and S. Wang, Pore network modeling of liquid water and oxygen transport through the porosity-graded bilayer gas diffusion layer of polymer electrolyte membrane fuel cells. Electrochimica Acta, 2019. 306: p. 264-276.

56. Zamel, N. and X. Li, Non-isothermal multi-phase modeling of PEM fuel cell cathode. International Journal of Energy Research, 2010. 34(7): p. 568-584.

57. Cao, T.-F., et al., Modeling the temperature distribution and performance of a PEM fuel cell with thermal contact resistance. International Journal of Heat and Mass Transfer, 2015. 87: p. 544-556.

58. Hashemi, F., S. Rowshanzamir, and M. Rezakazemi, CFD simulation of PEM fuel cell performance: Effect of straight and serpentine flow fields. Mathematical and Computer Modelling, 2012. 55(3): p. 1540-1557.

59. Mortazavi, M. and K. Tajiri. Impact of Gas Diffusion Layer Properties on Liquid Water Breakthrough Pressure in Polymer Electrolyte Fuel Cell. in ASME 2013 11th International Conference on Fuel Cell Science, Engineering and Technology collocated with the ASME 2013 Heat Transfer Summer Conference and the ASME 2013 7th International Conference on Energy Sustainability. 2013. American Society of Mechanical Engineers. 
60. Weber, A.Z. and J. Newman, Effects of membrane-and catalyst-layer-thickness nonuniformities in polymer-electrolyte fuel cells. Journal of the Electrochemical Society, 2007. 154(4): p. B405-B412.

61. Mittal, V.O., H.R. Kunz, and J.M. Fenton, Membrane degradation mechanisms in PEMFCs. Journal of The Electrochemical Society, 2007. 154(7): p. B652-B656.

62. Zhou, B., et al., Water and pressure effects on a single PEM fuel cell. Journal of Power Sources, 2006. 155(2): p. 190-202.

63. Secanell, M., et al., Multi-variable optimization of PEMFC cathodes using an agglomerate model. Electrochimica Acta, 2007. 52(22): p. 6318-6337.

64. Weber, A.Z., R.M. Darling, and J. Newman, Modeling two-phase behavior in PEFCs. Journal of the Electrochemical Society, 2004. 151(10): p. A1715-A1727.

65. Qu, S., et al., The effect of air stoichiometry change on the dynamic behavior of a proton exchange membrane fuel cell. Journal of Power Sources, 2008. 185(1): p. 302310.

66. Bernardi, D.M. and M.W. Verbrugge, A mathematical model of the solid-polymerelectrolyte fuel cell. Journal of the Electrochemical Society, 1992. 139(9): p. 2477-2491.

67. Pasaogullari, U. and C.-Y. Wang, Two-phase modeling and flooding prediction of polymer electrolyte fuel cells. Journal of The Electrochemical Society, 2005. 152(2): p. A380-A390.

68. Wang, Y. and X. Feng, Analysis of reaction rates in the cathode electrode of polymer electrolyte fuel cell I. Single-layer electrodes. Journal of The Electrochemical Society, 2008. 155(12): p. B1289-B1295.

69. Sander, R., Compilation of Henry's law constants for inorganic and organic species of potential importance in environmental chemistry. 1999, Max-Planck Institute of Chemistry, Air Chemistry Department Mainz, Germany.

70. Springer, T.E., T.A. Zawodzinski, and S. Gottesfeld, Polymer Electrolyte Fuel Cell Model. Journal of The Electrochemical Society, 1991. 138(8): p. 2334-2342.

71. Berning, T., M. Odgaard, and S.K. Kær, Water balance simulations of a polymerelectrolyte membrane fuel cell using a two-fluid model. Journal of Power Sources, 2011. 196(15): p. 6305-6317.

72. Cussler, E.L., Diffusion: Mass Transfer in Fluid Systems. 3rd ed. 2009: Cambridge University Press.

73. Bevers, D., et al., Simulation of a polymer electrolyte fuel cell electrode. Journal of Applied Electrochemistry, 1997. 27(11): p. 1254-1264.

74. Mandelbrot, B.B., The Fractal Geometry of Nature. 1983: W.H. Freeman, San Francisco.

75. Mandelbrot, B., Fractals and Chaos: The Mandelbrot Set and Beyond. 2004: SpringerVerlag, New York.

76. Vicsek, T., Fractal Growth Phenomena. 1989: World Scientific Publishing Company, Singapore.

77. Murray, C.D., The physiological principle of minimum work: I. The vascular system and the cost of blood volume. Proceedings of the National Academy of Sciences of the United States of America, 1926. 12(3): p. 207.

78. Gheorghiu, S., et al., Is the lung an optimal gas exchanger?, in Fractals in biology and medicine. 2005, Springer. p. 31-42.

79. Mauroy, B., et al., An optimal bronchial tree may be dangerous. Nature, 2004. 427: p. 633.

80. Sapoval, B., M. Filoche, and E.R. Weibel, Smaller is better-but not too small: A physical scale for the design of the mammalian pulmonary acinus. Proceedings of the National Academy of Sciences, 2002. 99(16): p. 10411-10416.

81. Andersson, M., et al., A review of cell-scale multiphase flow modeling, including water management, in polymer electrolyte fuel cells. Applied Energy, 2016. 180: p. 757-778. 
808

809

810

811

812

813

814

815

816

817

818

819

820

821

822

823

824

825

826

827

828

829

830

82. Cetinbas, F.C., et al., Microstructural Analysis and Transport Resistances of LowPlatinum-Loaded PEFC Electrodes. Journal of The Electrochemical Society, 2017. 164(14): p. F1596-F1607.

83. Gandomi, Y.A., et al., Water Management in Polymer Electrolyte Fuel Cells through Asymmetric Thermal and Mass Transport Engineering of the Micro-Porous Layers. Journal of The Electrochemical Society, 2016. 163(8): p. F933-F944.

84. Myles, T.D., et al., Application of an Effective Medium Formulation to Account for Transport Due to Fiber and Web-like Inclusions in Gas Diffusion Layers. Journal of The Electrochemical Society, 2015. 162(7): p. F645-F650.

85. Wang, Y. and S. Wang, Evaluation and modeling of PEM fuel cells with the Bruggeman correlation under various tortuosity factors. International Journal of Heat and Mass Transfer, 2017. 105: p. 18-23.

86. Wong, K.H. and E. Kjeang, Simulation of Performance Tradeoffs in Ceria Supported Polymer Electrolyte Fuel Cells. Journal of The Electrochemical Society, 2019. 166(2): p. F128-F136.

87. Ye, Q. and T. Van Nguyen, Three-dimensional simulation of liquid water distribution in a PEMFC with experimentally measured capillary functions. Journal of the Electrochemical Society, 2007. 154(12): p. B1242-B1251.

88. Natarajan, D. and T. Van Nguyen, Three-dimensional effects of liquid water flooding in the cathode of a PEM fuel cell. Journal of Power Sources, 2003. 115(1): p. 66-80.

89. Chen, L., Q. Kang, and W. Tao, Pore-scale study of reactive transport processes in catalyst layer agglomerates of proton exchange membrane fuel cells. Electrochimica Acta, 2019. 306: p. 454-465.

90. Nalbant, Y., C.O. Colpan, and Y. Devrim, Development of a one-dimensional and semiempirical model for a high temperature proton exchange membrane fuel cell. International Journal of Hydrogen Energy, 2018. 43(11): p. 5939-5950.

91. Randrianarizafy, B., et al., Design optimization of rib/channel patterns in a PEMFC through performance heterogeneities modelling. International Journal of Hydrogen Energy, 2018. 43(18): p. 8907-8926.

92. Rizvandi, O.B. and S. Yesilyurt, A pseudo three-dimensional, two-phase, nonisothermal model of proton exchange membrane fuel cell. Electrochimica Acta, 2019. 302: p. 180-197.

93. Sohn, Y.-J., et al., PEMFC modeling based on characterization of effective diffusivity in simulated cathode catalyst layer. International Journal of Hydrogen Energy, 2017. 42(18): p. 13226-13233.

94. Secanell, M., et al., Optimization of a proton exchange membrane fuel cell membrane electrode assembly. Structural and Multidisciplinary Optimization, 2009. 40(1): p. 563.

95. Litster, S., et al., Morphological Analyses of Polymer Electrolyte Fuel Cell Electrodes with Nano-Scale Computed Tomography Imaging. Fuel Cells, 2013. 13(5): p. 935-945.

96. Barbir, F., PEM fuel cells: theory and practice. 2nd ed. 2013, Amsterdam: Academic Press.

97. Smith, J.M., H.C. Van Ness, and M.M. Abbott, Introduction to Chemical Engineering Thermodynamics. 2005: McGraw-Hill.

98. Marquis, J., Nature-inspired hierarchically structured high-efficiency PEM fuel cell, in Chemical \& Biological Engineering. , 2013, Rensselaer Polytechnic Institute: Troy, NY, . p. 202.

99. Jang, J.-H., W.-M. Yan, and C.-C. Shih, Numerical study of reactant gas transport phenomena and cell performance of proton exchange membrane fuel cells. Journal of Power Sources, 2006. 156(2): p. 244-252.

100. Sun, W., B.A. Peppley, and K. Karan, Modeling the Influence of GDL and flow-field plate parameters on the reaction distribution in the PEMFC cathode catalyst layer. Journal of Power Sources, 2005. 144(1): p. 42-53. 
831

832

833

834

835

836

837

838

839

840

841

842

843

844

845

846

847

848

849

850

851

852

853

854

855

856

857

858

859

860

861

862

863

864

865

866

867

868

869

870

871

872

873

874

875

876

877

878

879
101. Chiang, M.-S. and H.-S. Chu, Numerical investigation of transport component design effect on a proton exchange membrane fuel cell. Journal of Power Sources, 2006. 160(1): p. 340-352.

102. Jeng, K.T., et al., Oxygen mass transfer in PEM fuel cell gas diffusion layers. Journal of Power Sources, 2004. 138(1): p. 41-50.

103. Jang, J.-H., W.-M. Yan, and C.-C. Shih, Effects of the gas diffusion-layer parameters on cell performance of PEM fuel cells. Journal of Power Sources, 2006. 161(1): p. 323332.

104. Guvelioglu, G.H. and H.G. Stenger, Computational fluid dynamics modeling of polymer electrolyte membrane fuel cells. Journal of Power Sources, 2005. 147(1-2): p. 95-106.

105. Cho, J.I.S., et al., Capillaries for water management in polymer electrolyte membrane fuel cells. International Journal of Hydrogen Energy, 2018. 43(48): p. 21949-21958.

106. Cho, J.I.S., et al., Visualization of liquid water in a lung-inspired flow-field based polymer electrolyte membrane fuel cell via neutron radiography. Energy, 2019. 170: p. 14-21.

107. Ye, G., et al., Method for generating pore networks in porous particles of arbitrary shape, and its application to catalytic hydrogenation of benzene. Chemical Engineering Journal, 2017. 329: p. 56-65.

108. Ye, G., et al., Pore network modeling of catalyst deactivation by coking, from single site to particle, during propane dehydrogenation. AIChE Journal, 2019. 65(1): p. 140150.

109. Eikerling, M. and A.A. Kornyshev, Modelling the performance of the cathode catalyst layer of polymer electrolyte fuel cells. Journal of Electroanalytical Chemistry, 1998. 453(1): p. 89-106.

110. Owejan, J.P., et al., Water Transport Mechanisms in PEMFC Gas Diffusion Layers. Journal of The Electrochemical Society, 2010. 157(10): p. B1456-B1464.

111. Thomas, A., et al., Thermal and water transfer in PEMFCs: Investigating the role of the microporous layer. International Journal of Hydrogen Energy, 2014. 39(6): p. 26492658.

112. Weber, A.Z. and M.A. Hickner, Modeling and high-resolution-imaging studies of watercontent profiles in a polymer-electrolyte-fuel-cell membrane-electrode assembly. Electrochimica Acta, 2008. 53(26): p. 7668-7674.

113. Zhang, Z., W. Liu, and Y. Wang, Three dimensional two-phase and non-isothermal numerical simulation of multi-channels PEMFC. International Journal of Hydrogen Energy, 2019. 44(1): p. 379-388.

114. Chen, L., et al., Nanoscale simulation of local gas transport in catalyst layers of proton exchange membrane fuel cells. Journal of Power Sources, 2018. 400: p. 114-125.

115. Greszler, T.A., D. Caulk, and P. Sinha, The Impact of Platinum Loading on Oxygen Transport Resistance. Journal of The Electrochemical Society, 2012. 159(12): p. F831F840.

116. Jinnouchi, R., et al., Molecular Dynamics Simulations on O2 Permeation through Nafion lonomer on Platinum Surface. Electrochimica Acta, 2016. 188: p. 767-776.

117. Kurihara, Y., T. Mabuchi, and T. Tokumasu, Molecular dynamics study of oxygen transport resistance through ionomer thin film on Pt surface. Journal of Power Sources, 2019. 414: p. 263-271.

118. Suzuki, T., K. Kudo, and Y. Morimoto, Model for investigation of oxygen transport limitation in a polymer electrolyte fuel cell. Journal of Power Sources, 2013. 222: p. 379-389. 